\title{
1 Design, Modeling, and Evaluation of a 2 Doublet Heat Extraction Model in 3 Enhanced Geothermal Systems
}

$4 \quad$ Yidong Xia*, Mitchell Plummer, Earl Mattson, Robert Podgorney

5 Idaho National Laboratory, 1955 N. Fremont Ave, P.O. Box 1625, Idaho Falls, ID 83415-2025

6 Ahmad Ghassemi

7 University of Oklahoma, 660 Parrington Oval, Norman, OK 73019

\section{ABSTRACT}

9 A conceptual Enhanced Geothermal System (EGS) model, where water is circulated through a pair of

10 parallel injection and production wells connected by a set of single large wing fractures, is designed,

11 modeled, and evaluated in this work. The water circulation and heat extraction in the fractured reser-

12 voirs is modeled as a fully coupled process of fluid flow and heat transport. Using a newly developed,

13 open-source, finite element based geothermal simulation code, FALCON, simulation results were ob-

14 tained for a 30-year operation at a depth of $3 \mathrm{~km}$ and geothermal gradient of $65^{\circ} \mathrm{C} \mathrm{per} \mathrm{km} \mathrm{of} \mathrm{depth.} \mathrm{With}$

15 a sensitivity study of the heat production to the design parameters, preferable fracture horizontal spac-

16 ing, downward deviation angle of the parallel wells, and injection flow rate are recommended. Upscaling

17 calculations of the developed EGS model have shown that, an industrial production-level system may be

18 achievable if it consists of 40 equidistant fractures that connect two $1.2 \mathrm{~km}$ long parallel well sections

19 with a well separation of $500 \mathrm{~m}$; and if a system of these dimensions operates for 30 years at a flow rate

20 of $0.1 \mathrm{~m}^{3} / \mathrm{s}$, with an electric power output at least $5 \mathrm{MW}$ and pumping power of less than $1 \mathrm{MW}$. In par-

21 ticular, the performance metrics demonstrated in this work match well with those suggested by others,

22 thus indicating the general applicability of our conceptual models.

\footnotetext{
* Corresponding email address: yidong.xia@inl.gov
} 
1 Keywords: Renewable energy, EGS, fractured reservoir, heat production, finite element method

\section{LIST OF SYMBOLS}

\begin{tabular}{lll} 
Symbols & Unit & Notation \\
$c_{\mathrm{w}}$ & $\mathrm{J} \cdot \mathrm{kg}^{-1} \cdot \mathrm{K}^{-1}$ & Specific heat capacity of fluid \\
$c_{\mathrm{r}}$ & $\mathrm{J} \cdot \mathrm{kg}^{-1} \cdot \mathrm{K}^{-1}$ & Specific heat capacity of rock \\
$g$ & $\mathrm{~m} \cdot \mathrm{s}^{-2}$ & Magnitude of gravitational force \\
$K_{\mathrm{m}}$ & $\mathrm{W} \cdot \mathrm{m}^{-1} \cdot \mathrm{K}^{-1}$ & Average thermal conductivity of the porous medium \\
$k$ & $\mathrm{~m}^{2}$ & Reservoir intrinsic permeability \\
$P e_{h}$ & -- & Element Peclet number \\
$p$ & $\mathrm{~Pa}$ & Fluid pressure \\
$Q$ & $\mathrm{~J} \cdot \mathrm{s}^{-1}$ & Thermal energy source/sink \\
$\mathbf{q}$ & $\mathrm{m} \cdot \mathrm{s}^{-1}$ & Flux (Darcy velocity) vector \\
$s$ & $\mathrm{~kg} \cdot \mathrm{m}^{-3} \cdot \mathrm{s}^{-1}$ & Specific mass source/sink (or specific injection/production rate) \\
$T$ & $\mathrm{~K}$ & Fluid temperature \\
$t$ & $\mathrm{~S}$ & Time \\
\hline & $\mathrm{Pa} \cdot \mathrm{s}$ & Fluid viscosity \\
$\rho$ & $\mathrm{kg} \cdot \mathrm{m}^{-3}$ & Fluid density \\
$\rho_{r}$ & $\mathrm{~kg} \cdot \mathrm{m}^{-3}$ & Rock density \\
\hline & -- & Reservoir porosity \\
\hline & $\mathrm{m}{ }^{-1}$ & Vector differential operator \\
\hline & &
\end{tabular}




\section{INTRODUCTION}

\section{$2 \quad 1.1$ Heat Extraction Process in EGS}

3 The concept of creating an engineered, or enhanced geothermal system (EGS) (Batchelor 1982, Cornet

4 1989), first described as a hot dry rock (HDR) system (Smith et al. 1975, Tester et al. 1989, Duchane

5 1990, and Duchane et al. 2002), originated at the Los Alamos National Laboratory (LANL) in the 1970s,

6 and is of continuing interest due to the need for low $\mathrm{CO}_{2}$-emission energy sources. Among the many as-

7 pects of EGS design, number and spacing of fractures, optimal placement of injection and production

8 wells, flow rates and pressures, are all critical factors affecting heat production performance. However,

9 largely due to the difficulty and expense of creating an EGS, many uncertainties exist regarding the op-

10 timal system design (U.S. Department of Energy 2008). Numerical modeling and simulation methods

11 provide one way of testing EGS design concepts, and incorporating much of the geometric complexity

12 and complicated physics of those designs.

13 Based on the various conceptual designs of EGS well layout, the heat extraction process has been in-

14 vestigated extensively in recent years. The well layout schemes that are often modeled include three

15 basic forms: 1) doublet (an injection and production well pair), 2) triplet (an injector flanked by a pro-

16 duction well on each side), and 3) five-spot (an injector at the center and a production well at each cor-

17 ner of a square). Due to the great volume of literature published in this area, only some of the most re-

18 cent works are reviewed here. Sanyal et al. 2005 simulated a 30-year power generation period of a 3D

19 hypothetical EGS model with a five-spot well layout, and analyzed the optimal performance of the mod-

20 el by performing a sensitivity study on fracture spacing, reservoir permeability, and well geometry. Zeng

21 et al. 2013(a) investigated the performance of a 2D conceptual EGS model with a horizontal doublet well

22 layout, and concluded that the energy efficiency mainly depends on the reservoir permeability and the

23 water production rate. Jiang et al. 2014 designed and simulated a 40-year heat extraction period of a 3D 
1 conceptual EGS with a triplet well layout, and demonstrated that it is able to retain the preferential flow

2 in the reservoir and significantly elongate the heat production by 10 years over its doublet counterpart.

3 Chen et al. 2015 conducted a comparative study on the long-term performance between a doublet

4 scheme, two triplet schemes, and a five-spot scheme for well layouts. Their results have showed that

5 the performance of EGS could not be necessarily improved by simply deploying more production wells.

6 Later on, Chen at al. 2016 performed a detailed sensitivity study of design parameters for the EGS heat

7 extraction process with a doublet well, and revealed that the heat extraction rate and lifetime of the

8 system are tightly related to the flow pattern in the reservoir, while the thermal compensation from

9 rocks surrounding the reservoir contributes little heat to the working fluid if the operation period is

10 short. Though most of those works were based on hypothetical models that assumed isotropic and ho-

11 mogeneous subsurface environment, they have substantially advanced our understanding of how to op-

12 timize the long-term performance of the EGS heat extraction process.

\subsection{Numerical Modeling and Simulation Methods}

14 Modeling the operation of an EGS plant requires reliable numerical methods to simulate the coupled

15 thermal-hydraulic-mechanical (THM) processes. Nevertheless, the mechanical interaction between rock

16 and fluid as well as the rock thermoelastic effect has been often neglected for simulating long-term EGS

17 heat extraction process in many recent studies (with the reasons to be discussed later). For example,

18 Zeng et al. 2013(a), Zeng et al. 2013(b) and Bujakowski et al. 2015 used the finite difference method

19 (FDM) based TOUGH2 code (Pruess et al. 1999) for simulating the heat extraction process from EGS sys-

20 tems. However, FDM has a known disadvantage in that it requires high-quality structured meshes to ob-

21 tain accurate solution, which could largely limit the complexity of the fracture features to be modeled.

22 Though the FDM can also handle irregular meshes, the use of irregular meshes, in turn, could result in

23 overly diffused solutions of convection-dominated heat transport in fractured reservoirs, which might

24 lead to significantly inaccurate estimates of EGS design parameters. The inconvenience associated with 
1 FDM triggered the use of unstructured mesh based methods, such as the finite volume methods (FVMs)

2 and finite element methods (FEMs). For example, based on the computational fluid dynamics (CFD)

3 solver, Fluent ${ }^{\circledR}$, Jiang et al. 2014 developed a 3D hydrothermal flow model that uses the cell-centered

$4 \quad$ FVM for solving the transient incompressible flow and heat transfer with the Navier-Stokes equations in

5 both the reservoirs and wells. It was then applied in an extensive study of EGS well layouts (Chen at al.

6 2015, and Chen et al. 2016). However, it is not clear if their first-order FVM spatial discretization scheme

7 was able to retain sufficient solution accuracy for long-term simulation of convective heat transport in

8 fractured reservoirs. Alternatively, the Galerkin FEMs and so-called "Control-Volume" FEM (CV-FEM,

9 nothing but the node-centered FVM) may offer more flexibility for reservoir modeling, as they support

10 the implementation of 1D, 2D, and 3D elements in the same model (e.g., in a 3D EGS model, the frac-

11 tures can be represented with 2D planar surfaces embedded in 3D rock matrix, and the wells can be rep-

12 resented with 1D curves). Examples include the "FEHM" code developed at LANL (Zyvoloski 2007), the

13 "FRACTure" code by Kohl et al. 1995 and applied in Held et al. 2014, and the "PANDAS" code by Xing at

14 al. 2015. However, so far most of the FEM codes are not as powerful as the mature FDM code such as

15 TOUGH2 to model some very complex problems, such as the coupled THMC processes (where " $\mathrm{C}$ "

16 stands for chemical reactions). Further development of the FEM based numerical methods to overcome

17 their existing weaknesses is in urgent demand.

\section{$18 \quad 1.3$ Objectives and Novelties}

19 The objectives of the present work are to evaluate performance of several variants of a common con-

20 ceptual EGS model. In this model, water is circulated through two parallel wells connected by a set of

21 single large wing fractures in a fully saturated geothermal reservoir (see Figure 1). The sensitivity of EGS

22 heat production to some key design parameters, including the fracture horizontal spacing, flow rate, and

23 well deviation angle, will be assessed, respectively. A newly developed, open-source FEM based geo-

24 thermal simulation code, FALCON (Xia et al. 2015), has been used for the simulations. The novelty of this 
1 work is two-fold. First, a mixed-dimensional rock-fracture model is employed, where the fractures are

2 represented using 2D planar domains that are embedded in a 3D domain that represents the surround-

3 ing rock matrix, with the same governing equations applied in both domains. Unlike the 2D single frac-

4 ture model used in Zeng et al. 2013, our 3D model takes into account the inter-fracture thermal inter-

5 ference, for which the long-term impact on the production wellbore temperature cannot be neglected

6 where the fractures are spaced at reasonable distances. Second, this work considers a doublet parallel

7 well layout with a downward deviation angle, and compares its performance to a similar system of hori-

8 zontal wells. Third, open-source FALCON code used, and the simulation files for this study, are available

9 to the public for continued development and/or testing of other scenarios.

10 The rest of this paper is organized as follows: Section 2 presents the governing equations for the

11 coupled fluid flow and heat transport in geothermal reservoir environment, and constitutive models for

12 calculating the density and viscosity of liquid-phase water. Section 3 describes the proposed 3D concep-

13 tual EGS model. Section 4 reports the numerical results of the simulation test cases and sensitivity anal-

14 ysis. Finally, Section 5 gives concluding remarks and outlook for future work.

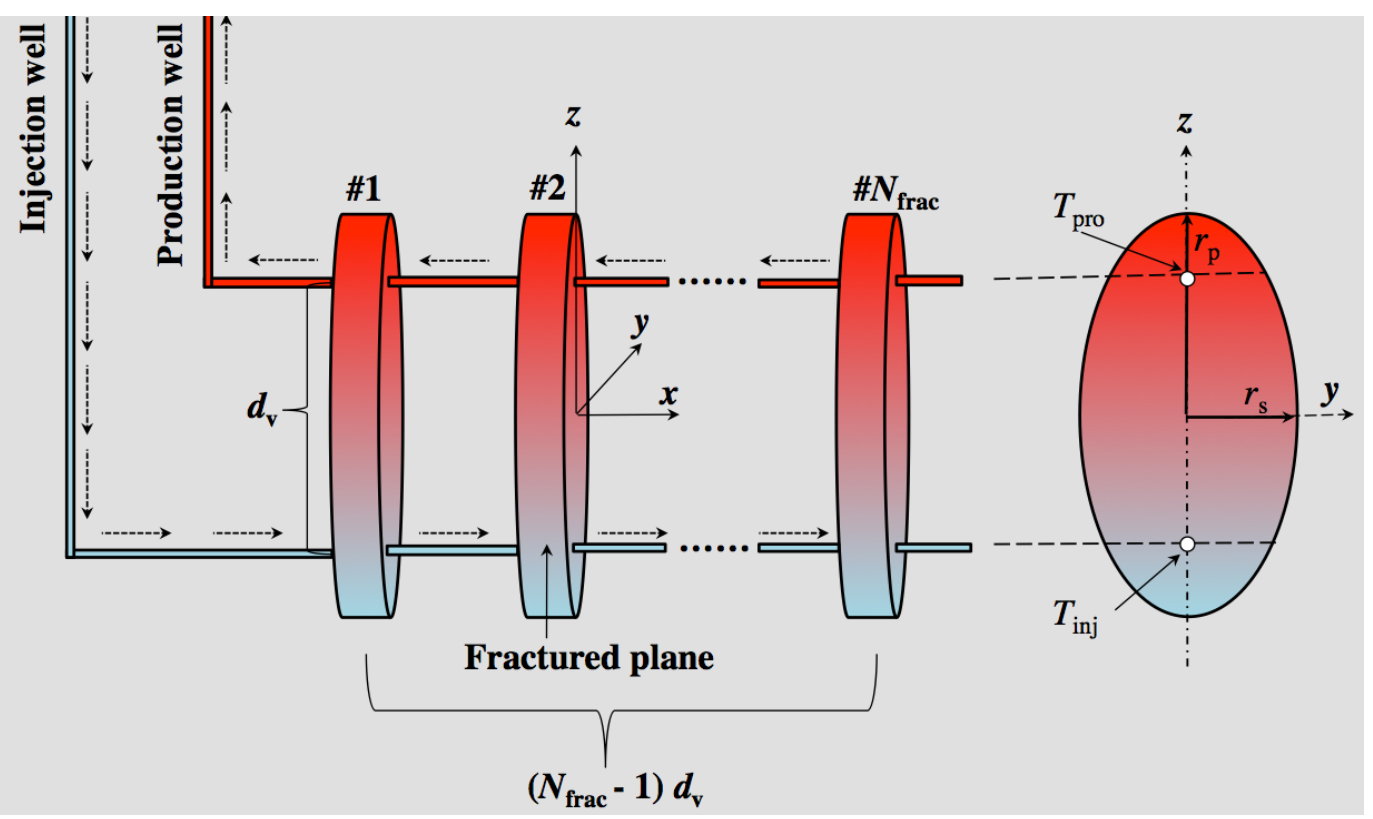




\section{Mathematical Model}

2 Initially introduced in Podgorney et al. 2010, our geothermal simulation code, FALCON, featured a paral-

3 lel, fully implicit capability for modeling the fully coupled THM processes in a singly integrated code.

$4 \quad$ FALCON has been developed using both pressure-temperature (P-T) and pressure-enthalpy (P-H) formu-

5 lations (Podgorney at al. 2011). The P-T formulation is limited to the modeling of single-phase water-

6 saturated systems, while the P-H formulation can be used for both single- and two-phase systems. The

7 P-T based liquid flow and heat transport module of the FALCON code is used for the reservoir simula-

8 tions in this work. This module has been rigorously validated through a number of benchmark problems

9 in Xia et al. 2016b, and made available as an open-source toolkit (Xia et al. 2015).

\section{$10 \quad 2.1$ Governing Equations}

11 The mathematical models describing geothermal systems can be found in Brownell et al. (1977), Faust \&

12 Mercer (1979a), and Faust \& Mercer (1979b). In the P-T based formulation for a single-phase water-

13 saturated system, mass conservation for the fluid phase in the porous medium may be written as:

$$
\frac{\partial(\phi \rho)}{\partial t}+\boldsymbol{\nabla} \cdot(\rho \mathbf{q})-s=0
$$

15 When considering momentum conservation of the system, we assume that Darcy's law is valid, and that

16 momentum balance for the fluid phase may be represented as:

$\mathbf{q}=-\frac{k}{\mu}(\nabla p+\rho g \nabla z)$

18 where $\nabla z$ is a vector of components $(0,0,-1)$, when the gravity force is taken to align in the negative

19 vertical direction. Combining Eq. (1) and Eq. (2) yields the following equation for liquid-phase water

20 flow in a deformable, compressible geologic medium:

$$
\frac{\partial(\phi \rho)}{\partial t}-\boldsymbol{\nabla} \cdot\left(\frac{k}{\mu} \rho(\nabla p+\rho g \nabla z)\right)-s=0
$$


1 If we assume that the thermal equilibrium exists between the fluid and solid phases, the energy conser-

2 vation can be described as below:

$\frac{\partial\left[\phi \rho c_{\mathrm{w}}+(1-\phi) \rho_{\mathrm{r}} c_{\mathrm{r}}\right] T}{\partial t}-\nabla \cdot\left(K_{\mathrm{m}} \nabla T\right)+\boldsymbol{\nabla} \cdot\left(T \rho c_{\mathrm{w}} \mathbf{q}\right)-\dot{Q}=0$

3

4

5

6 the following:

$\phi \frac{\partial \rho}{\partial p} \frac{\mathrm{d} p}{\mathrm{~d} t}+\boldsymbol{\nabla} \cdot \mathbf{q}_{\mathrm{M}}-s=0$

$C_{\mathrm{m}} \frac{\mathrm{d} T}{\mathrm{~d} t}-K_{\mathrm{m}} \boldsymbol{\nabla} \cdot \boldsymbol{\nabla} T+\boldsymbol{\nabla} \cdot\left(T \mathbf{q}_{\mathrm{E}}\right)-\dot{Q}=0$

7

8 Eq. (5) and Eq. (6) are the P-T based governing equations being used in this work, where the terms $\rho \mathbf{q}$,

$9 \phi \rho c_{\mathrm{w}}+(1-\phi) \rho_{\mathrm{r}} c_{\mathrm{r}}$, and $\rho c_{\mathrm{w}} \mathbf{q}$ are replaced by $\mathbf{q}_{\mathrm{M}}, C_{\mathrm{m}}$, and $\mathbf{q}_{\mathrm{E}}$, respectively, for simplicity. In the FAL-

10 CON code, the Galerkin finite element method is used for the spatial discretization of the governing

11 equations above, and the second-order backward Euler method (BDF2) is used for the time integration

12 of the resulting nonlinear system of equations. Detailed description of the numerical methods imple-

13 mented in the FALCON code can be found in Xia et al. 2016a.

\section{$14 \quad 2.2$ Constitutive Relationships}

15 The FALCON code has adopted the IAPWS industrial formulation 1997 (denoted IAPWS-97) to calculate

16 the phase thermodynamic properties (i.e., density, internal energy, and viscosity) of water and/or steam

17 (Wagner et al. 2000). This formulation uses pressure ( $\leq 100 \mathrm{MPa})$ and temperature $\left(\leq 800^{\circ} \mathrm{C}\right)$ as input pa-

18 rameters, and returns density and internal energy, which can be applied in the liquid water, steam and

19 supercritical regions. The formula of viscosity in IAPWS-97 uses density and temperature as input varia-

20 bles, and returns fluid viscosity of either water or steam, depending on the input density value. An up-

21 date to the IAPWS-97 formulation was released in 2008 (Cooper et al. 2008) and has also been imple- 
1 mented. Our earlier study shows that satisfactory results were obtained with the IAPWS-97 model in a

2 series of benchmark test problems in single-phase water-saturated systems (Xia et al. 2016b).

\section{$3 \quad 3$ THE CONCEPTUAL MODEL}

\section{$4 \quad 3.1 \quad$ Fractured Reservoir}

5 Our reservoir model is comprised of two distinct, but connected domains. These are (1) un-fractured

6 rock matrix blocks and (2) fractures that separate those blocks. The matrix blocks and fractured reser-

$7 \quad$ voirs are both treated as slightly compressible homogeneous porous media, where the coupled flow and

8 heat transport may be represented by Eq. (5) and Eq. (6). These assumptions have been adopted in

9 many recent studies, including, for example, Sanyal et al. 2005, Jiang et al. 2014, Bujakowski et al. 2015,

10 and Chen at al. 2016.

11 The characteristics of a multi-dimensional fractured reservoir network, such as the permeability, ap-

12 erture and fracture geometric shapes, may be subject to change during the heat production process of

13 an EGS. Modeling the coupled THM processes in the fractured reservoir normally requires an explicit de-

14 scription of fracture distribution that resolves many aspects of the rock physics, for example, variations

15 of fracture aperture with respect to local effective stress, rock deformations due to shear failure, and

16 constitutive relationships between the fracture aperture and fracture thermal conductivity as well as

17 thermo-elasticity. Modeling the coupled THM processes instead of TH may result in a more accurate but

18 also significantly more complex EGS model for the heat production process. In one study of the impacts

19 of different coupled processes on EGS performance (e.g., hydro-mechanical and thermo-hydro-

20 mechanical), McDermott et al. 2006 showed that the productivity of the reservoir is lower when fluid

21 properties in fractured reservoir are functions of only fluid pressure and temperature, and rock mechan-

22 ical properties are assumed constant. This is mainly because the permeability of the fracture system will

23 increase as the reservoir is cooled if hydroelastic and/or thermoelastic interactions between the rock 
1 and fluid are considered (McDermott et al. 2006). Hence, a lower productivity may be estimated in the

2 case that the physical properties of rock are constant in the system. Thus, in our conceptual EGS reser-

3 voir model, we consider it a conservative assumption that, after the man-made fractures have been cre-

4 ated by stimulation, the mechanical properties of the fractured reservoir remain unchanged during the

5 heat production process.

\section{$6 \quad 3.2$ Well Layout}

7 As illustrated in Figure 1, two horizontally parallel doublet wells are connected by a set of vertically ex-

8 tended, equidistant single wing fracture planes, where $N_{\text {frac }}$ is the total number of fracture planes. The

9 vertical distance between the lower injection well and the higher production well is denoted by $d_{\mathrm{v}}$. The

10 horizontal spacing between each two neighboring fracture planes is denoted by $d_{\mathrm{h}}$. In Figure 1 , the

11 thickness of the planar fractures is exaggerated for visualization purpose only, and is very thin compared

12 to the other dimensions of the plane. The fractures can therefore be treated as zero-thickness planar

13 geometry by neglecting mass and heat transport in the across-plane direction. The geomechanics of cre-

14 ation of this type of fracture were discussed in Jung 2013, and Li \& Lior 2015. According to Jung 2013,

$1530 \sim 40$ such fractures may be required to achieve the desired thermal productivity. To lower the compu-

16 tational burden of simulating a system containing that many fractures, we created a reduced-scale

17 model that contains only five fractures (see Figure 2). While symmetry of the problem for the horizontal

18 well problem would allow a single-fracture representation, the 5-fracture domain allows comparison of

19 the performance of the inclined and horizontal borehole scenarios. The fractures are numbered from \#1

20 to \#5 along the $\mathrm{x}$-direction and the midpoint of the \#3 fracture is chosen as the reference depth, $z_{\text {ref }}$, be-

21 low the ground surface. We assume a geothermal gradient of $65^{\circ} \mathrm{C}$ per $\mathrm{km}$ of depth in our imaginary

22 subsurface domain, and specify a reference temperature of $200^{\circ} \mathrm{C}$ and reference pressure of $30 \mathrm{MPa}$ at

23 our reference depth of $-3 \mathrm{~km}$. We believe this reduced-scale model is sufficient to reveal the sensitivity

24 of long-term heat production performance to the design parameters of interest, and through symmetry 
1 can be used to estimate the performance of the full-scale model. In addition to the horizontal well lay-

2 out, an alternative well layout with a downward inclination angle of $\alpha=45^{\circ}$ is also considered (see Figure

$32 \mathrm{~b})$. Because an inclined system of fractures reduces the total drilling distance, the goal here is to com-

4 pare performance of these two systems when other factors are held constant. Well drilling is a very ex-

5 pensive process in terms of the capital investment (Barbier 2002, and Polsky et al. 2008), so system de-

6 sign that minimizes drilling is usually preferred. To make a fair comparison of heat production perfor-

7 mance between these two well layouts, the $d_{\mathrm{v}}$ and $d_{\mathrm{h}}$ are kept identical between the two scenarios.

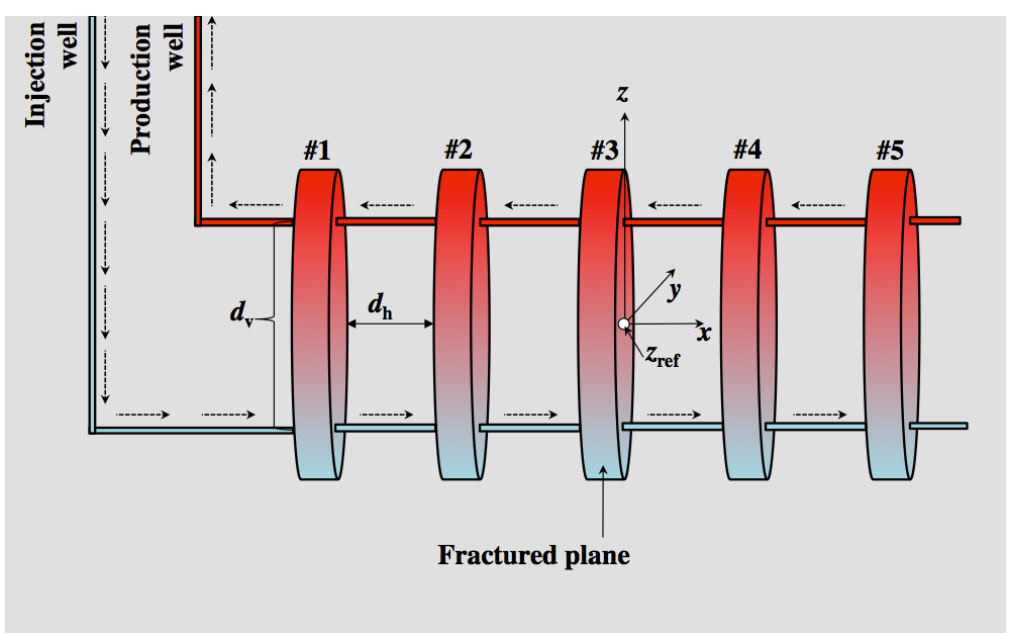

(a)

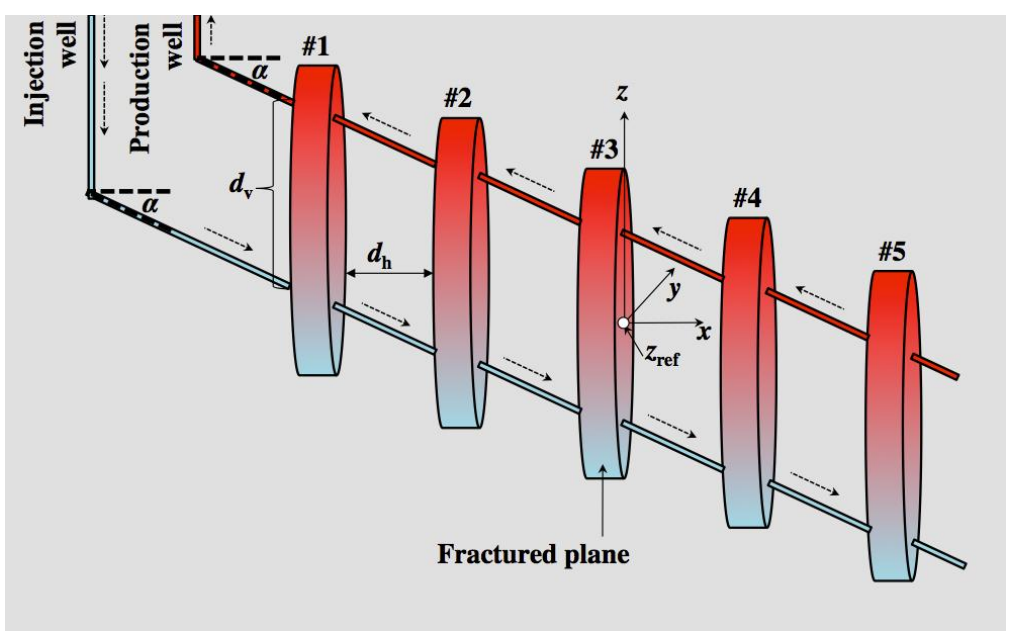

(b)

8 Figure 2 Two reduced-scale well layout schemes: (a) horizontally parallel doublet wells, (b) parallel doublet wells with a downward deviating angle of $\alpha$. 
To complete the water circulation and heat production processes, an injection pump that connects the injection well and a suction pump that connects the production well are installed on the ground. We assume that the water mass rate from each injection wellbore into the fracture plane is constant. The suction pump draws the heated water out of the reservoir through the production well, and pumps the into the fractured reservoir via the injection well.

\section{$7 \quad 3.3$ Geometric Configuration and Domain Discretization}

8 Figure 3 illustrates the two steps to create the geometric configuration and the finite element mesh for

9 our hypothetical geological system: 1), the creation of a 2D domain and mesh; and 2), the creation of a 10 mixed-dimensional 2d-fracture/3d-matrix system. The CUBIT toolkit (Blacker et al. 1994) is used for cre-

11 ating the geometry and meshes. Due to the symmetry of our model in the $x$-z plane, only half of the

12 domain is modeled. In step 1, a 2D planar fracture-matrix system is created in the $y-z$ plane with the $x-$

13 coordinate equal to zero, where the fracture (colored in red) is represented by a semielliptical disk with

14 a primary radius of $r_{p}=750 \mathrm{~m}$ in the z-direction and secondary radius of $r_{s}=500 \mathrm{~m}$ in the $\mathrm{y}$-direction

15 (see Figure 3a). The fracture is encompassed by the rock matrix (colored in grey) whose outer boundary

16 is represented by a semicircular curve with a radius of $1 \mathrm{~km}$. Due to the absence of actual data of such a

17 single large fracture, its shape and size are determined hypothetically, but reasonably enough to indi-

18 cate the directions of the minimum and maximum in situ stresses in the initial stimulation process. No-

19 tice that since we are not interested in the near-wellbore flow behaviors, the fluid injection and pump-

20 ing is modeled using two semicircular boundary curves with a relatively large radius of $2 \mathrm{~m}$, and aligned

21 vertically with $d_{\mathrm{v}}=500 \mathrm{~m}$. The $2 \mathrm{D}$ domain is then discretized using the quadrilateral elements, most of

22 which are clustered near the injection and production boundaries. This simplification of wellbore geom-

23 etries can help substantially reduce the total elements of the mesh, and improve the efficiency of solv- 
1 ing. Also notice that the simulated physical quantities at the injection and production boundaries of our

2 computational domain only represent their values near the wellbore, but not right at the wellbores.

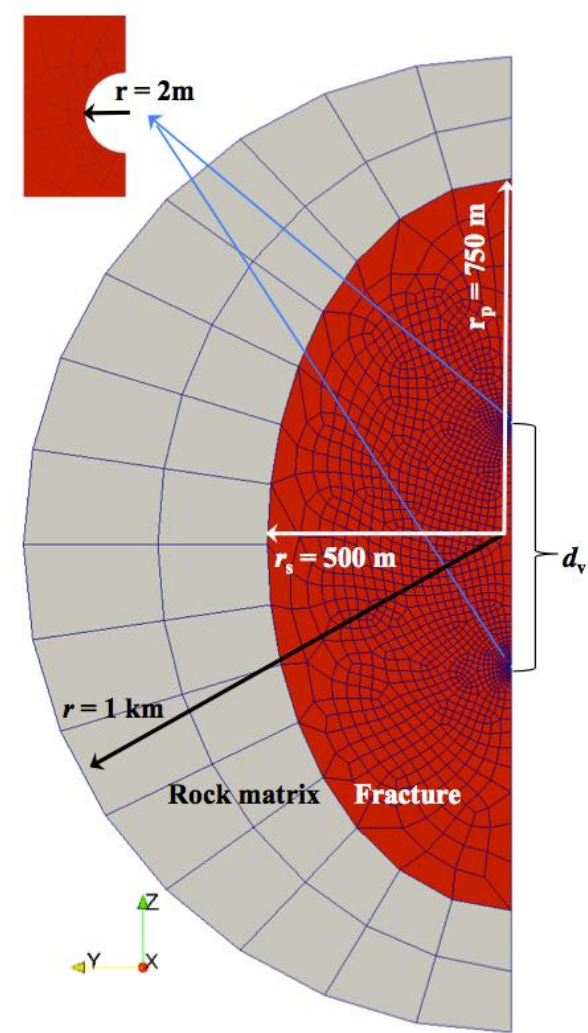

(a)

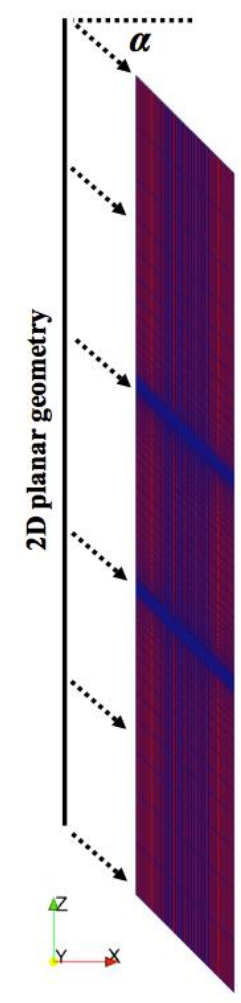

(b)

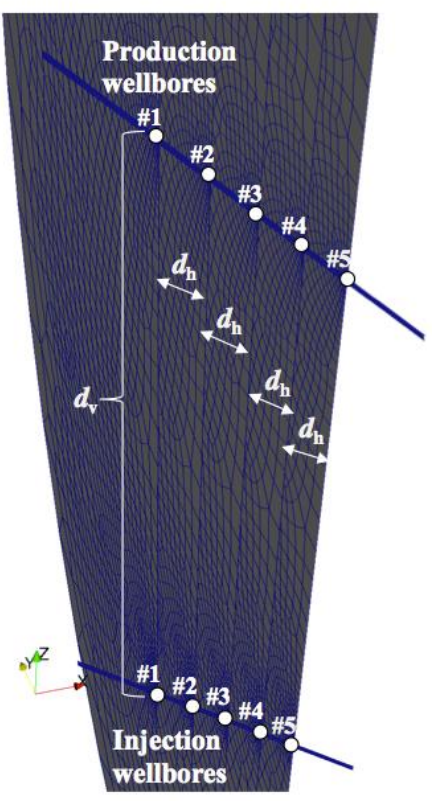

(c)

Figure 3 The mixed-dimensional geometric configurations and meshes of the EGS model: (a) the initial 2D geometry; (b) the extrusion from 2D to 3D along the direction of wells; (c) the five planar fractures.

In step 2, the 2D planar geometry is extruded in the $x$-direction for a total horizontal length equal to $4 d_{\mathrm{h}}+2 d_{\mathrm{ex}}$, with an optional downward deviating angle, $\alpha=0^{\circ}$ or $45^{\circ}$ (see Figure 3b). The resulting 3D block is then split by a plane normal to the $x$-direction at locations $x=d_{\mathrm{ex}}$ (tagged \#1), $d_{\mathrm{ex}}+d_{\mathrm{h}}(\# 2)$,

$9 d_{\mathrm{ex}}+2 d_{\mathrm{h}}(\# 3), d_{\mathrm{ex}}+3 d_{\mathrm{h}}(\# 4)$, and $d_{\mathrm{ex}}+4 d_{\mathrm{h}}(\# 5)$, respectively, as shown in Figure $3 \mathrm{c}$. The $d_{\mathrm{ex}}$ is the ex-

10 tra horizontal space beyond the first and last fracture planes, and it has to be wide enough (i.e., $d_{\mathrm{ex}}=$

$1160 \mathrm{~m}$ ) so as not to let the cooling front reach the far-field boundary at the end of simulations. Thanks to

12 its mixed-dimensional modeling capability, the FALCON code allows zero-thickness planes to represent

13 the fractures surrounded by the 3D matrix blocks. It was shown in Reichenberger et al. 2006 that the use

14 of lower-dimensional fractures in higher-dimensional reservoirs could reduce the computational costs, 
1 and also improve the efficiency of implicit time integration. Finally, 10 and 15 equidistant layers of hex-

2 ahedral elements are filled for the sub-blocks between each two neighboring fractures, and for the sub-

3 blocks of the extra space beyond the first and last fractures, respectively. Thus a 3D mesh with any com-

4 bination of $d_{\mathrm{h}}$ and $\alpha$ will result in the same total number of elements $(111,160)$ and points $(118,570)$.

\section{$5 \quad 3.4$ Boundary Conditions}

6 A number of common boundary conditions (BCs) have been implemented in the FALCON code. Three

7 basic BCs for the mass conservation in Eq. (5) include: a) the Dirichlet pressure BC; b) the Neumann

8 mass flux $B C$, with which a mass flux normal to the boundary face, $-\mathbf{q}_{M} \cdot \mathbf{n}$, can be prescribed at the

9 wellbore boundaries; and c) the Neumann free outflow BC, with which the $\mathbf{q}_{M}$ values at the quadrature

10 points of a boundary face are interpolated from the host boundary element. Likewise, three basic BCs

11 for energy conservation in Eq. (6) include: a) the Dirichlet temperature BC; b) the Neumann heat inflow

$12 \mathrm{BC}$, with which a heat flux normal to a boundary face, $\left(-K_{\mathrm{m}} \boldsymbol{\nabla} T+T \mathbf{q}_{\mathrm{E}}\right) \cdot \mathbf{n}$, can be fixed at the injection

13 wellbore boundary; and c) the Neumann heat outflow BC, with which the heat flux $\mathbf{q}_{\mathrm{E}}$ value at the quad-

14 rature points of a boundary surface are interpolated from the host boundary element.

15 For our EGS model depicted in Figure 3, a constant mass flux with fixed re-injection water tempera-

16 ture of $80^{\circ} \mathrm{C}$ is imposed at each of the five injection boundaries (see Figure 3c). The heat outflow condi-

17 tions are prescribed at each of the five production boundaries, with a fixed reference fluid pressure of

$1830 \mathrm{MPa}$ at the \#3 production boundary. No-flow boundaries for both fluid and heat (i.e., zero pressure

19 gradient and zero temperature gradient) are imposed at the $x-z$ symmetry plane and at the far-field

20 boundary.

\section{$21 \quad 3.5$ Reservoir Material Properties}

22 The material properties of a dual-porosity/dual-permeability subsurface environment for our conceptual

23 EGS model are summarized in Error! Reference source not found., where both the fracture planes and 
1 rock matrix blocks are considered as fully-saturated, isotropic, homogeneous porous medium. Notice

2 that in our numerical model, the unity thickness, i.e., $1 \mathrm{~m}$, is used for fracture planes. This indicates that,

3 if one assumes the fracture planes to be $1 \mathrm{~cm}$-thick, the actual fracture permeability can be considered

4 as 100 times larger than the input value. In this work, an input value of $0.5 \times 10^{-12} \mathrm{~m}^{2}$ was chosen for the

5 permeability of the fracture planes. This value was determined based on a detailed sensitivity study of

6 design constraints (Plummer et al. 2016). Noticed that a larger permeability should result in a higher

7 power production rate but also a shorter overall production stage. On the other hand, a smaller perme-

8 ability might not provide sufficient power production rate as needed. Other properties, such as permea-

9 bility of the matrix zone, porosity and thermal conductivity, were determined according to the docu-

10 mented data of the Eastern Snake River Plain, Idaho (Blackwell et al. 1992). Recently, Zeng et al. 2013a

11 and Zeng et al. 2013b had systematically investigated optimization of these properties in an EGS. Thus

12 we chose to not further extend this discussion in this work.

13 Table 1: Material properties used in the test cases

\begin{tabular}{l|l}
\hline Parameters & Values \\
\hline Density of the rock & $\begin{array}{l}2700 \mathrm{~kg} / \mathrm{m}^{3} \\
\text { Computed from IAPWS-97 } \\
\text { Density of the fluid }\end{array}$ \\
$\begin{array}{l}\text { Viscosity of the fluid } \\
1.0 \times 10^{-20} \mathrm{~m}^{2}\end{array}$ \\
$\begin{array}{l}\text { Permeability of the matrix zone } \\
\text { Permeability of the fractured zone }\end{array}$ & $\begin{array}{l}0.5 \times 10^{-12} \mathrm{~m}^{2} \\
\text { Porosity of the matrix zone }\end{array}$ \\
$\begin{array}{l}\text { Porosity of the fractured zone } \\
\text { Specific heat capacity of the matrix zone }\end{array}$ & $790 \mathrm{~J} /(\mathrm{kg} \mathrm{K})$ \\
Specific heat capacity of the fluid & $4818 \mathrm{~J} /(\mathrm{kg} \mathrm{K})$ \\
Medium average thermal conductivity of the matrix zone & $3.0 \mathrm{~W} /(\mathrm{m} \mathrm{K})$ \\
Medium average thermal conductivity of the fractured zone & $1.5 \mathrm{~W} /(\mathrm{m} \mathrm{K})$
\end{tabular}




\subsection{Initial Conditions}

2 A steady-state simulation of fluid flow is conducted first, to obtain a pressure distribution with a con-

3 stant density and viscosity of water evaluated at average reservoir conditions. A time-dependent simula-

4 tion of the coupled fluid flow and heat transport is then started, where the initial condition (IC) for pres-

5 sure is taken from the result of the first simulation. A linear distribution of the initial temperature along

6 the $z$-direction is specified in the field based on $z_{\text {ref }}=3 \mathrm{~km}$. The geothermal gradient is specified as $65^{\circ} \mathrm{C}$

7 per km of depth, representing the higher end of the range of values measured in the Eastern Snake River

8 Plain (Blackwell et al. 1992). As a result, the initial temperature at $z=z_{\text {ref }}$ is $200^{\circ} \mathrm{C}$, and the difference of

9 temperature between the injection and production boundaries in each fractured plane is $32.5^{\circ} \mathrm{C}$.

\section{NUMERICAL RESULTS}

11 As listed in Table 2, four test cases have been designed with the combinations of three parameters: 1)

12 the fracture horizontal spacing, $d_{\mathrm{h}}, 2$ ) the downward deviating angle of the parallel wells, $\alpha$, and 3) the

13 injection mass flow rate per fracture, $q$. Most of the material properties for water and rock have been

14 kept constant, while the density and viscosity of water are treated as functions of pressure and temper-

15 ature of water, and are calculated using the IAPWS-97 formulation. According to the three geometric

16 scenarios in Table 2, three meshes were generated and used for the simulations, respectively. The injec-

17 tion of cool water is started at time $=0$, and terminated after 30 years of operation.

18 Table 2: Configuration parameters used in the four simulations.

\begin{tabular}{l|ccc}
\hline Test Case & $d_{h}(\mathrm{~m})$ & $\alpha$ & $\dot{q}(\mathrm{~kg} / \mathrm{s})$ \\
\hline 1 (base) & 30 & $0^{\circ}$ & 3.14 \\
2 & 50 & $0^{\circ}$ & 3.14 \\
3 & 30 & $45^{\circ}$ & 3.14 \\
4 & 30 & $45^{\circ}$ & 6.28 \\
\hline
\end{tabular}

19 


\section{$1 \quad 4.1$ The Base Case}

2 We chose Test Case $1\left(d_{h}=30 \mathrm{~m}, \alpha=0^{\circ}, \dot{q}=3.14 \mathrm{~kg} / \mathrm{s}\right)$ as the base case for the initial validation of our

3 conceptual model in terms of some important EGS performance metrics. Notice that in order to deter-

4 mine if grid resolution of the mesh used in this work (111,160 elements and 118,570 points) is sufficient,

5 we carried out a grid dependence study by running the simulation on a uniformly refined mesh (i.e. each

6 hexahedral element was split into eight), and found that in this base case, the key performance metrics

7 (as will be described later) obtained on the refined mesh differed no more than $1.2 \%$ from those calcu-

8 lated on the original mesh. Assuming such level of errors from the grid resolution is negligible, we used

9 the original mesh in the rest of the test cases, since it is much cheaper in terms of computational costs.

\section{$10 \quad$ 4.1.1 Production Temperature and Thermal Energy Production Rate}

11 The thermal energy production rate from each fracture plane, $Q_{\text {pro }}(\mathrm{J} / \mathrm{s})$, can be calculated using the fol-

12 lowing area integral equation at the production boundary of each fracture plane:

$Q_{\text {pro }}=\int_{A_{\mathrm{b}}}\left(T_{\text {pro }}-T_{\text {inj }}\right) \mathbf{q}_{\mathrm{E}} \cdot \mathbf{n} \mathrm{d} \Gamma$

14 where $T_{\mathrm{inj}}=80^{\circ} \mathrm{C}$ is the temperature of the re-injection fluid, $T_{\text {pro }}$ the temperature of the produced fluid

15 that changes with time. We assume that no further electricity power can be produced when $T_{\text {pro }}$ drops

16 down below $160^{\circ} \mathrm{C}$.

17 In our numerical model, a complete heat extraction process may be considered to comprise two

18 stages: first a stable (production) stage, and then a declining stage. The stable stage is when $T_{\text {pro }}$ stays

19 above or at its initial value measured at the production wellbores. In the stable stage, the thermal ener-

20 gy production can be sustained above its initial rate, and the output electricity power can be steadily

21 transmitted. The declining stage starts when $T_{\text {pro }}$ drops below its initial value, and lasts until no electric

22 power can be generated. If we assume only a fraction of the extracted thermal energy can be converted

23 into the useful electric power through a binary plant, and further on a fraction of the generated electric 
1 power can be transmitted to the end consumers, the final effective electric power rate, $Q_{\text {eff }}$, can be ap-

2 proximated as follows,

$Q_{\text {eff }}=c_{\text {eff }} Q_{\text {pro }}$

3

4

5 this present study. ing of $d_{h}=30 m$, which is not wide enough to avoid inter-fracture interference. In addition, it is worth of

21 mentioning that the computational results obtained in this case were validated independently by Plum-

22 mer et al. 2016 in a comparative study, where a similar problem was setup and simulated using the

$23 \mathrm{COMSOL}^{\circledR}$ Multiphysics modeling software. 


\section{$1 \quad$ 4.1.2 Spatial Temperature Distribution}

2 Figure 5 shows the evolution of the cooled regions in the reservoir over the 30 -years operation, where

3 the cooled regions are highlighted using the solid volume with the lower and upper thresholds as $80^{\circ} \mathrm{C}$

4 and $160^{\circ} \mathrm{C}$, respectively, indicating the regions that no more effective thermal energy can be further ex-

5 tracted. After the operation begins, the cooled region in each fracture plane grows gradually from the

6 injection boundaries in an annular shape (Figure $5 \mathrm{~b}-\mathrm{c}$ ). During the initial 16.5 years of operation, the an-

7 nular cooled regions grow steadily, except when the cooling fronts reach the lower end of the fracture-

8 matrix interface. Meanwhile, the thermal energy near the injection wells are extracted first, and the

9 temperature around the production boundaries remains above $183.75^{\circ} \mathrm{C}$. From the 17 th year on, the

10 outer boundaries of the cooled regions start to bulge out toward the production boundaries quickly

11 (Figure 5 e-f), and the temperature near the production boundaries falls below its initial level, which

12 marks the beginning of the declining stage. It also indicates that the thermal energy near the production

13 boundaries starts being extracted.

\section{$14 \quad$ 4.1.3 Up-scaling and Performance Evaluation}

15 An industrial production-scale EGS requires a significantly larger electric power capacity than that of our

16 five-fracture model. As previously discussed, a well doublet system in a reservoir consisting of large sin-

17 gle-wing fractures should contain 30 to 40 equidistant fractures connecting two 1-km long parallel well

18 sections with a well separation of about $500 \mathrm{~m}$; and a system of these dimensions should operate for at

19 least 25 years at a flow rate of $0.1 \mathrm{~m}^{3} / \mathrm{s}$, and an electric power output between 5 and $10 \mathrm{MW}$ and pump-

20 ing power of less than $1 \mathrm{MW}$ (Jung 2013). Aiming to identify similar performance, we up-scaled the five-

21 fracture system based on the least performing fracture \#3, and obtained an average $Q_{\text {eff }}$ of about 5.6

22 MW with 40 fractures for a 30-year operation period. The resulting metrics indicate an acceptable level

23 of performance for our conceptual EGS model. Note that the thermal energy production rate may be

24 improved if rock deformation due to thermo-elasticity is considered (McDermott et al. 2006), although 
1 that effect could also lead to the increased short-circuiting, as flow through the cooled regions of the

2 flow system increases preferentially. In general, however, the presented conceptual EGS model can be

3 regarded as reasonable in terms of thermal energy production rate for long-term operations.

\section{$4 \quad 4.2$ Sensitivity Analysis of Design Constraints on Heat Production}

5 Following the base case, the simulated time histories of $T_{\text {pro }}$ and $Q_{\text {eff }}$, as well as the evolution of cooled

6 regions for the other three test cases (as listed in Table 2) are shown in Figure 6 - Figure 11, respectively.

7 Now with the results from these four test cases, it is possible to assess the sensitivity of heat production

8 to the following design parameters in our conceptual EGS model: 1) $d_{\mathrm{h}}$;2) $\alpha$; and 3) q́. Since the \#3 frac-

9 ture plane has been observed as the least performing one in each of the four test cases, we have chosen

10 the results obtained from those \#3 fracture planes for a comparative study.

\section{$11 \quad 4.2 .1$ Sensitivity to $d_{\mathrm{h}}$}

12 The sensitivity of heat production to $d_{\mathrm{h}}$ can be assessed by increasing $d_{\mathrm{h}}$ from $30 \mathrm{~m}$ in Test Case 1 to $1350 \mathrm{~m}$ in Test Case 2, while $\alpha=0^{\circ}$ and $\dot{q}=3.14 \mathrm{~kg} / \mathrm{s}$ in both cases. Figure 12 a-d show the dependence of

$14 T_{\mathrm{pro}}, P_{\mathrm{inj}}, Q_{\mathrm{eff}}$, and cumulative electric power production, $\sum\left(Q_{\mathrm{eff}} \Delta t\right)$, on $d_{\mathrm{h}}$, respectively, where $Q_{\mathrm{eff}}$ and $15 \sum\left(Q_{\mathrm{eff}} \Delta t\right)$ are multiplied by an upscale factor of 40 to measure the performance of a full-scale model 16 containing 40 of such fractures. As seen in Figure 12a, the stable stage in Test Case 2 lasts 22.5 years -6

17 years longer than that in Test Case 1 . Noticeably, $T_{\text {pro }}$ reaches the peak value of $192^{\circ} \mathrm{C}$ in both cases at 18 the 7th year, but declines faster in Test Case 1 since the 8th year, because of the earlier occurrence of 19 the inter-fracture interference (see Figure $5 \mathrm{~d}$ ). The $T_{\text {pro }}$ in the $\# 3$ fracture has dropped $13^{\circ} \mathrm{C}$ in Test Case

201 (Figure 4a). In comparison, the inter-fracture interference in Test Case 2 is very weak, as the $T_{\text {pro }}$ in the $21 \# 3$ fracture is only $4^{\circ} \mathrm{C}$ lower than that of the best performing fracture at the end of the 30th year

22 (Figure 6a). This leads to a difference in the up-scaled $\sum\left(Q_{\mathrm{eff}} \Delta t\right)$ by $125 \times 10^{6} \mathrm{kWh}$ after 30 -years (Figure 
1 12d). Besides, the total increase of $P_{\text {inj }}$ in Test Case 2 is $25 \%$ lower than that in Test Case 1 (Figure 12b),

2 indicating the slightly lower impedance for water reinjection and thus higher system efficiency.

3 The above analysis indicates that $d_{\mathrm{h}}$ is an important design constraint in our conceptual EGS model.

4 Though the inter-fracture interference could be completely avoided during the EGS lifetime given a suf-

5 ficiently large $d_{\mathrm{h}}$, it might require substantially more capital investment for the horizontal well drilling

6 process. For example, the distance for horizontal drilling will be more than $2 \mathrm{~km}$ if $d_{\mathrm{h}}$ is $50 \mathrm{~m}$ and $N_{\text {frac }}$ is

740 , which may not be economically feasible at all. Besides, the choice of $d_{\mathrm{h}}$ is tied to other constraints,

8 for example, the vertical distance between the injection and production wells, $d_{\mathrm{v}}$. Li \& Lior 2015 have

9 demonstrated a conceptual EGS reservoir similar to ours in terms of the layout of wells and fractures:

10 five large fracture planes with $d_{\mathrm{v}}=1 \mathrm{~km}$ and $d_{\mathrm{h}}=120 \mathrm{~m}$. The scales of the fractures involved in such

11 models emphasizes certain difficulties of construction, including that of creating such large fractures,

12 with $d_{\mathrm{v}} / d_{\mathrm{h}} \sim 10: 1$, without fracturing the rock matrix between the fractures; in addition to the difficulty

13 of consistently creating such large fractures in the desired locations.

\section{$14 \quad 4.2 .2$ Sensitivity to $\alpha$}

15 The sensitivity of heat production to $\alpha$ can be assessed by changing $\alpha$ from $0^{\circ}$ in Test Case 1 to $45^{\circ}$ in

16 Test Case 3 , while $d_{\mathrm{h}}=30 \mathrm{~m}$ and $\dot{q}=3.14 \mathrm{~kg} / \mathrm{s}$ in both cases. Figure $13 \mathrm{a}-\mathrm{d}$ show the dependence of $T_{\text {pro }}$,

$17 P_{\mathrm{inj}}, Q_{\mathrm{eff}}$, and $\sum\left(Q_{\mathrm{eff}} \Delta t\right)$, on $\alpha$, respectively. Again, $Q_{\mathrm{eff}}$ and $\sum\left(Q_{\mathrm{eff}} \Delta t\right)$ are both upscaled by a factor of 40

18 to indicate the performance of a full-scale model that contains 40 of such fractures. The change of $\alpha$ has

19 led to no major variation in the time histories of performance metrics, except for some slight difference

20 in the evolutions of $T_{\text {pro }}$ and $Q_{\text {eff. }}$ This has confirmed that the average impact of inter-fracture interfer-

21 ence to the \#3 fracture plane in Test Case 3 is close to that in Test Case 1, no matter what $\alpha$ is. As is well

22 known, a major geotechnical challenge for deep borehole drilling is how to efficiently overcome the in-

23 creasing in situ stress along the vertical direction. In reality, it may not be always possible to drill straight

24 vertical to reach the designed underground depth and desirable reservoir temperature, considering the 
1 uncertainties of actual distribution of reservoir physical properties. Therefore, on one side, a well layout

2 such as in Test Case 3 might relief some geotechnical difficulties for well drilling. But on the other side,

3 longer drilling distance is required for creating the same horizontal fracture spacing, which indicates

4 higher costs. To conclude, though potential advantages of the well layout design in Test Case 3 may not

5 be reflected through hydrothermal simulations, yet $\alpha$ is an important practical design. Further questions

6 such as whether or not to choose a typical downward deviating angle $\alpha$, or even a variable $\alpha$ at different

7 ranges of depth, vary case by case. To guide a well layout design in a realistic EGS system, sufficient in

8 situ stress data are required to model the creation of wells for determining a proper choice of $\alpha$.

\section{$9 \quad 4.2 .3$ Sensitivity to q́}

10 The sensitivity of heat production to $q$ can be assessed by raising $q$ from $3.14 \mathrm{~kg} / \mathrm{s}$ in Test Case 3 to

$116.28 \mathrm{~kg} / \mathrm{s}$ in Test Case 4, while $d_{\mathrm{h}}=30 \mathrm{~m}$ and $\alpha=45^{\circ}$ in both cases. Figure 14a-d show the dependence of

$12 T_{\mathrm{pro}}, P_{\mathrm{inj}}, Q_{\mathrm{eff}}$, and $\sum\left(Q_{\mathrm{eff}} \Delta t\right)$ on $\dot{q}$, respectively. With the injection mass flow rate doubled in Test Case

134 , the stable production stage is able to last for only 5.5 years, due to the early thermal breakthrough as

14 observed: $T_{\text {pro }}$ drops quickly since the 6 th year of operation, and the production life is over at the end of

15 the 17th year (see Figure 14a-b). By comparing Test Case 3 with Test Case 4, it has been clearly shown

16 that a higher q́ may lead to a higher $Q_{\text {eff }}$ during the early period of production, but may also result in a

17 significantly shortened stable production stage and total lifespan of the EGS site if $q$ is too high. Moreo-

18 ver, the average increment of $P_{\text {inj }}$ over the production life in Test Case 4 is over four times higher than

19 that in Test Case 3 (see Figure 14d), indicating a substantial increase of the required power for the water

20 reinjection process. Indeed, a long lasting stable level of $Q_{\text {eff }}$ as well as the other metrics is more prefer-

21 able for operation and management of the power plant. Therefore, despite the doubled $Q_{\text {eff }}$ for the ini-

22 tial few years of production, the simulated history of EGS performance in Test Case 4 is rather unfavora-

23 ble, because of the overly shortened stable production stage and total lifespan. As analyzed above, the

24 choice of $q$ h has profound impact on the output electric power rate and lifespan of the EGS. An optimal $q$ 
1 depends on various factors, such as the desired $Q_{\text {eff, }}$ production lifetime, and the cost of electric power

2 for reinjection and pumping. From the perspective of numerical modeling, sufficient time will be possi-

3 ble for hot fractured reservoir to heat the circulating water and $\mathrm{T}_{\text {pro }}$ could stay in the stable production

4 stage over an entire lifetime of an EGS site, when q́ is under a reasonable condition. To achieve such an

5 ideal conceptual EGS model, probably some EGS parameters have to be assumed as extremely favora-

6 ble, e.g., $d_{\mathrm{v}}=1 \mathrm{~km}$ (Li \& Lior 2015). However, as discussed in Section 4.2.1, it has yet to be investigated

$7 \quad$ whether those parameters are ever realistic.

8 


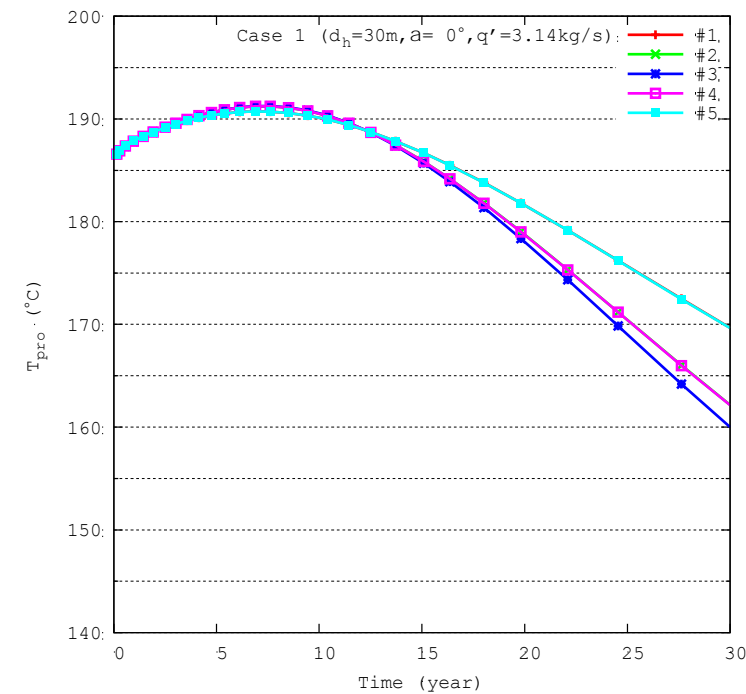

(a)

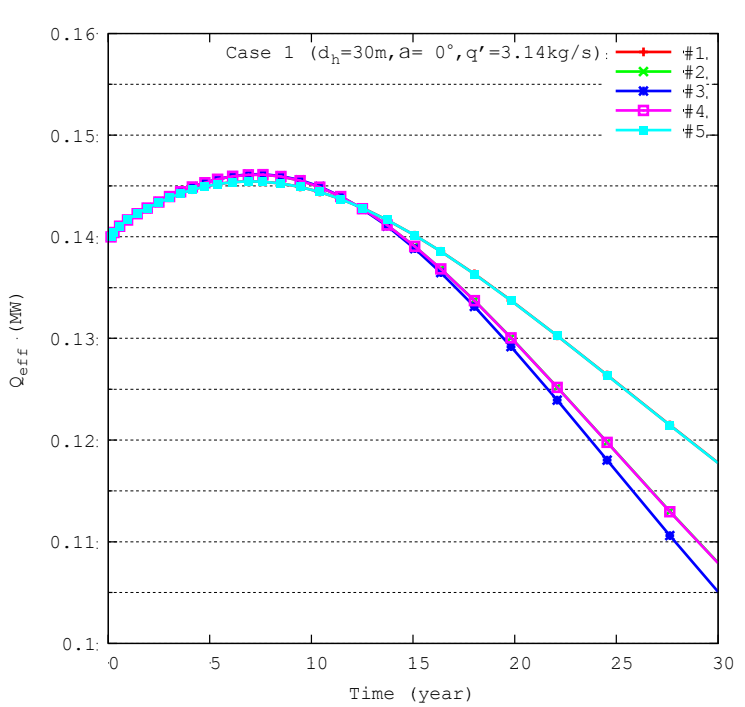

(b)

Figure 4 Time histories of (a) the produced fluid temperature from the five production boundaries and

(b) the corresponding effective electric power rates for Case $1\left(d_{\mathrm{h}}=30 \mathrm{~m}, \alpha=0^{\circ}, \dot{q}=3.14 \mathrm{~kg} / \mathrm{s}\right)$.

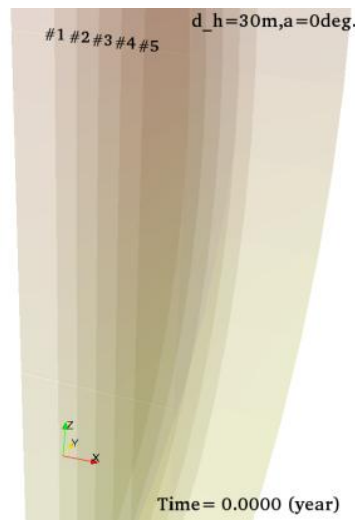

(a)

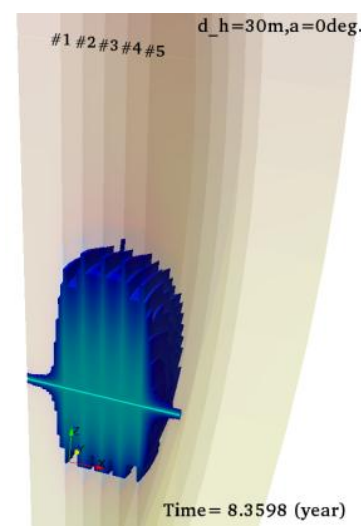

(d)

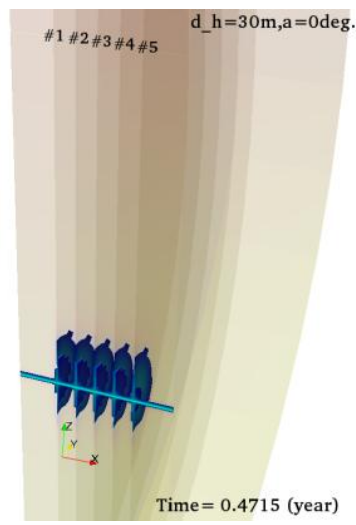

(b)

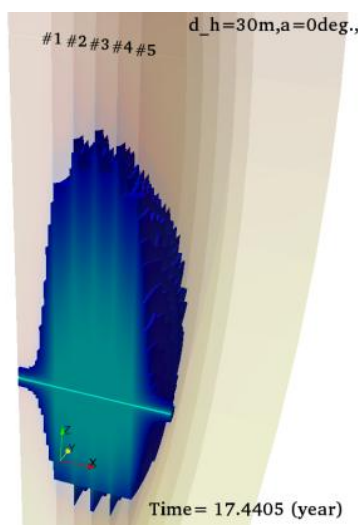

(e)

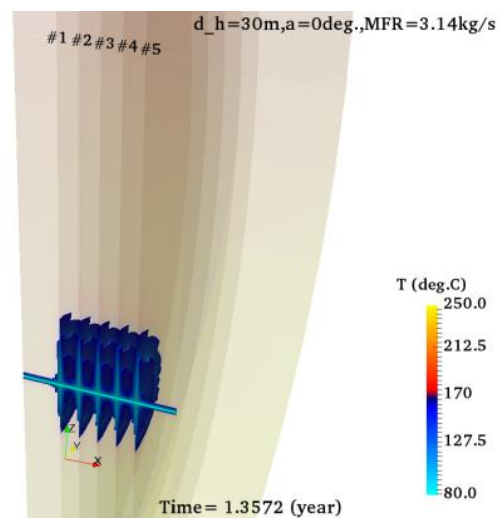

(c)

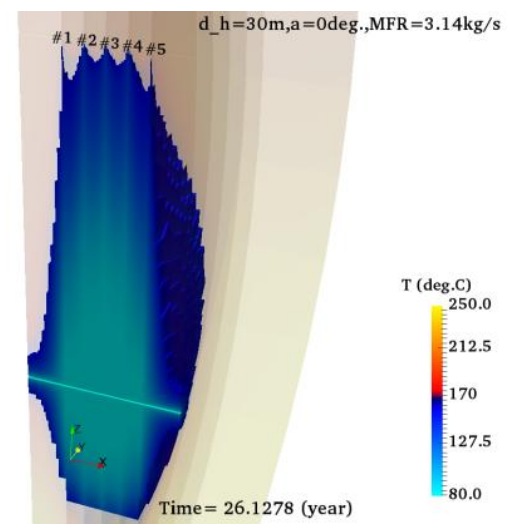

(f)

3 Figure 5 Evolution of the cooled regions in the reservoir for Case $1\left(d_{\mathrm{h}}=30 \mathrm{~m}, \alpha=0^{\circ}, \dot{q}=3.14 \mathrm{~kg} / \mathrm{s}\right)$. 


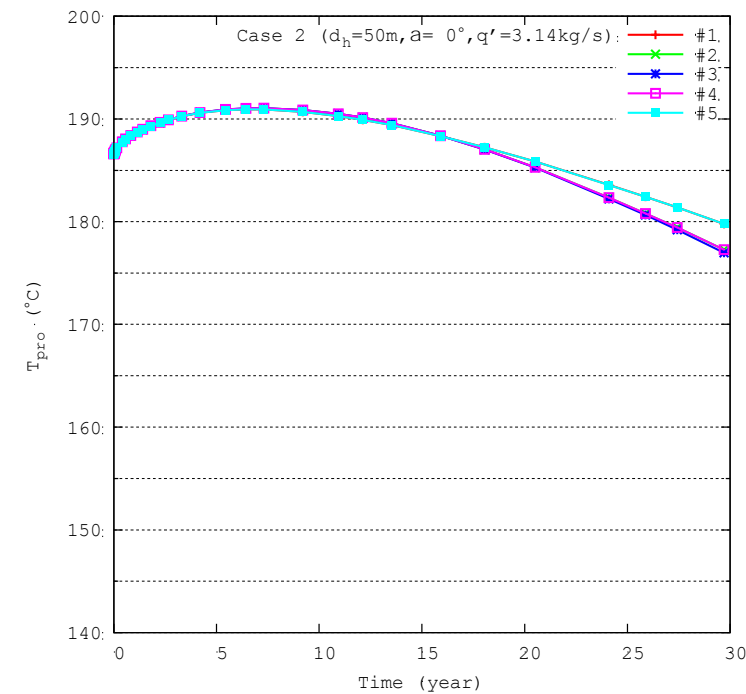

(a)

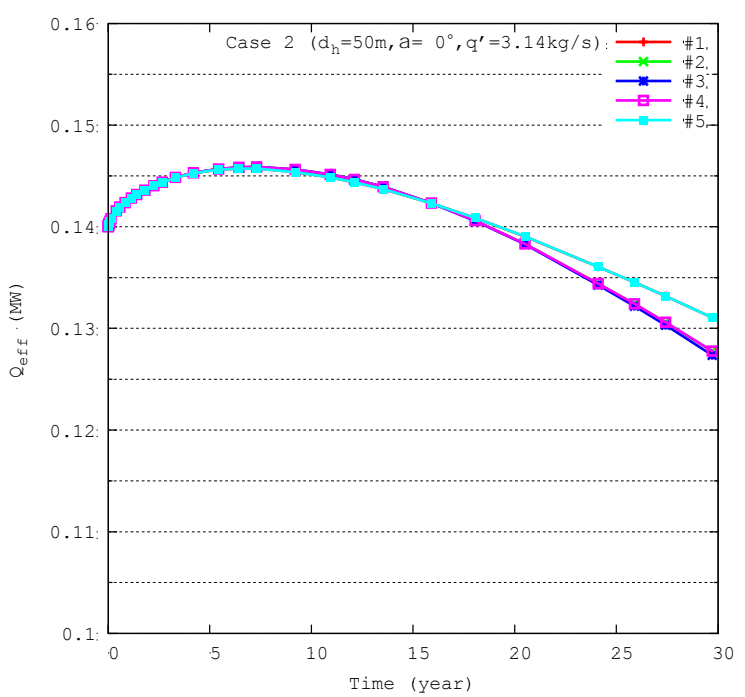

(b)

Figure 6 Time histories of (a) the produced fluid temperature from the five production boundaries and

(b) the corresponding effective electric power rates for Case $2\left(d_{\mathrm{h}}=50 \mathrm{~m}, \alpha=0^{\circ}, \dot{q}=3.14 \mathrm{~kg} / \mathrm{s}\right)$.

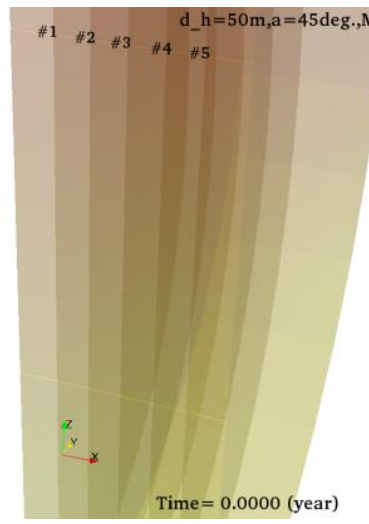

(a)

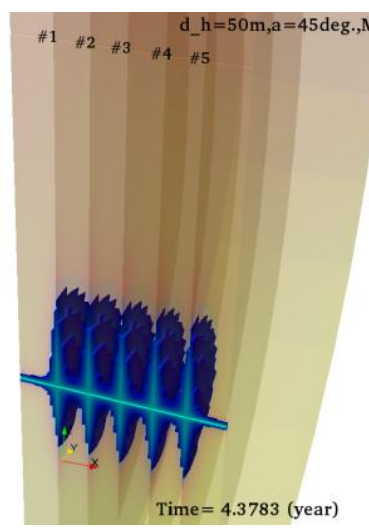

(d)

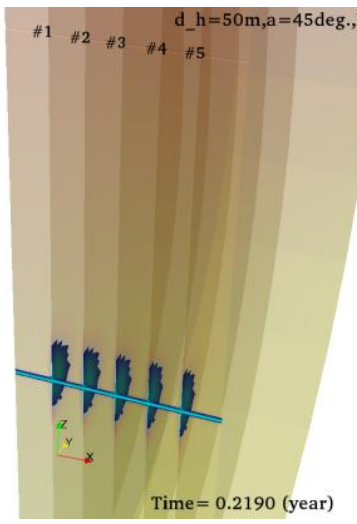

(b)

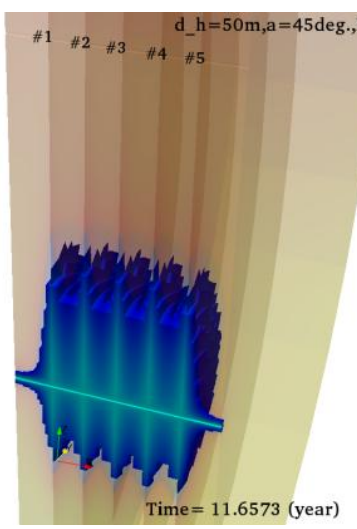

(e)

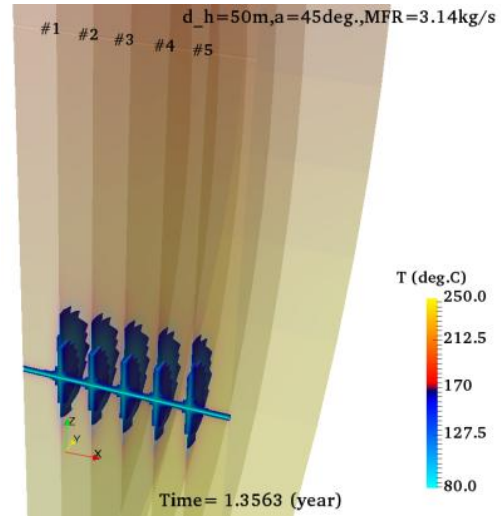

(c)

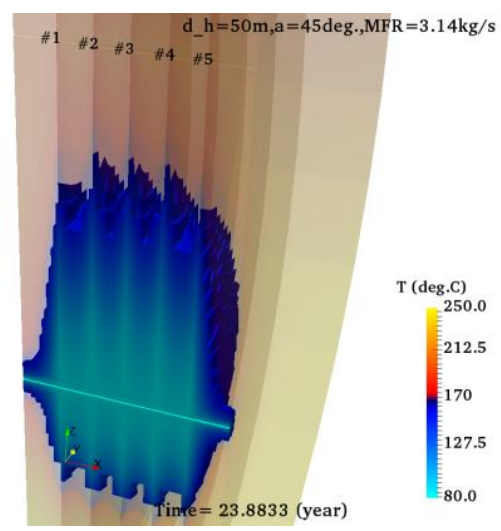

(f)

3 Figure 7 Evolution of the low-temperature regions in the reservoir for Case $2\left(d_{\mathrm{h}}=50 \mathrm{~m}, \alpha=0^{\circ}\right.$, 


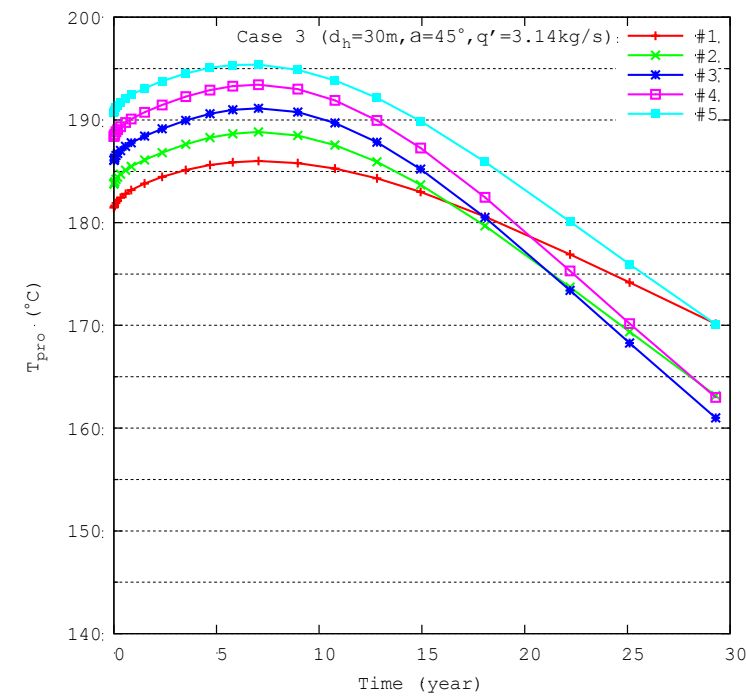

(a)

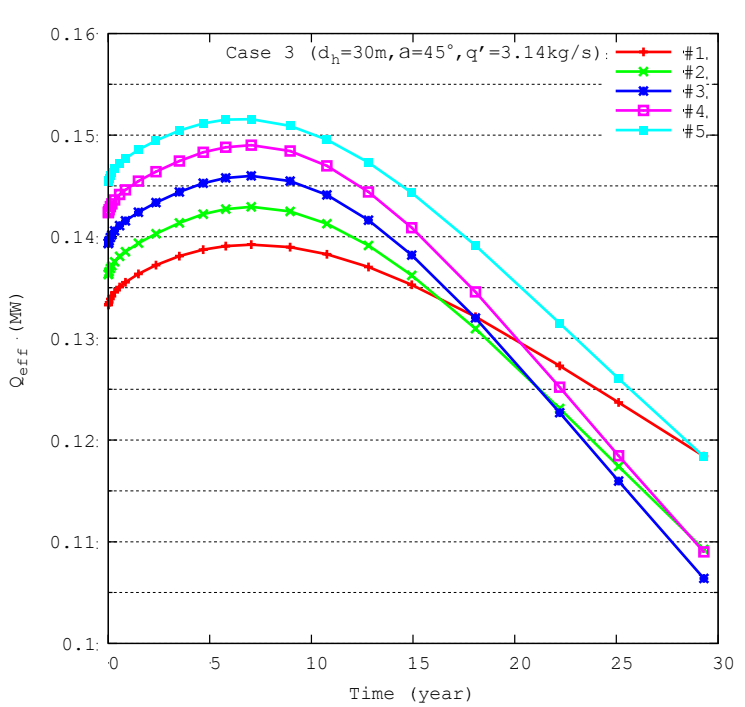

(b)

Figure 8 Time histories of (a) the produced fluid temperature from the five production boundaries and

2 (b) the corresponding effective electric power rates for Case $3\left(d_{\mathrm{h}}=30 \mathrm{~m}, \alpha=45^{\circ}, \dot{q}=3.14 \mathrm{~kg} / \mathrm{s}\right)$.

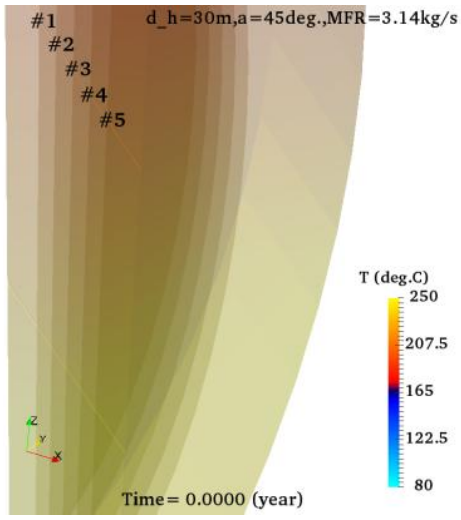

(a)

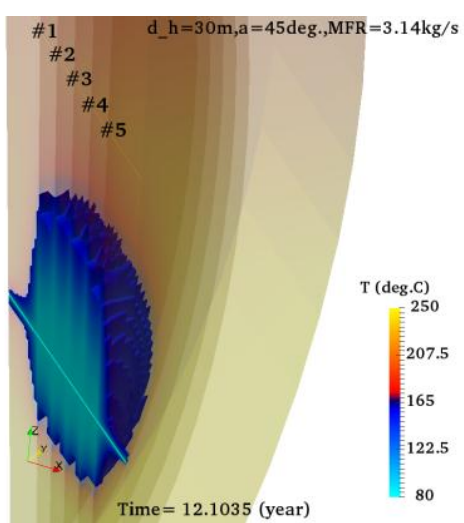

(d)

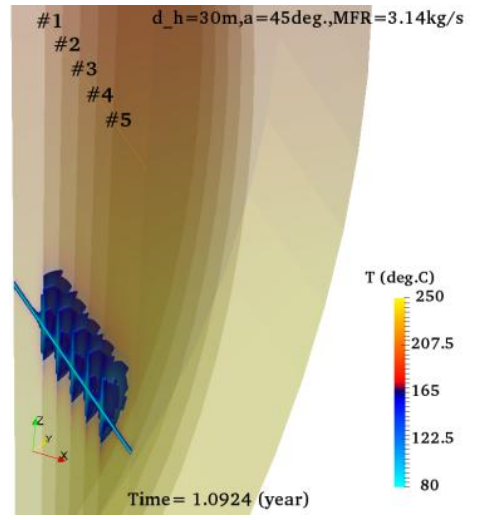

(b)

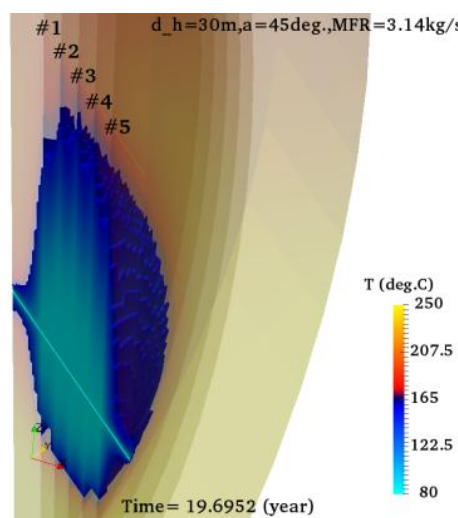

(e)

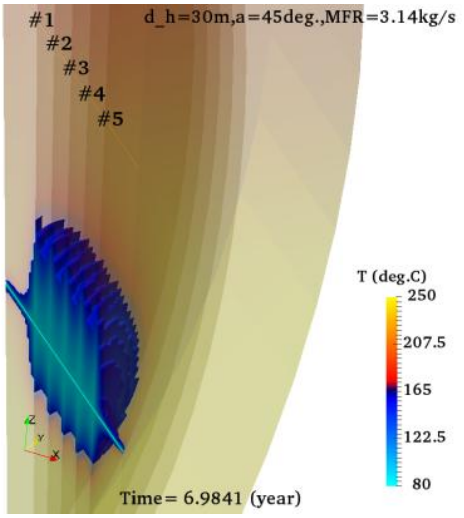

(c)

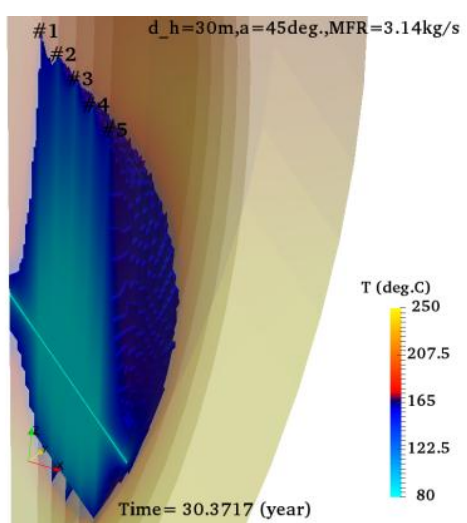

(f)

3 Figure 9 Evolution of the cooler regions in the reservoir for Case $3\left(d_{\mathrm{h}}=30 \mathrm{~m}, \alpha=45^{\circ}, \dot{q}=3.14 \mathrm{~kg} / \mathrm{s}\right)$. 


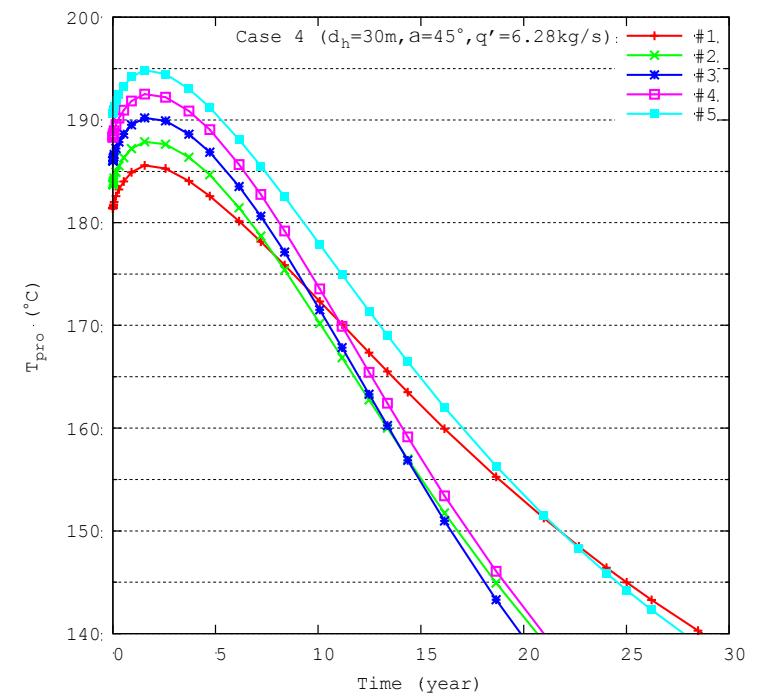

(a)

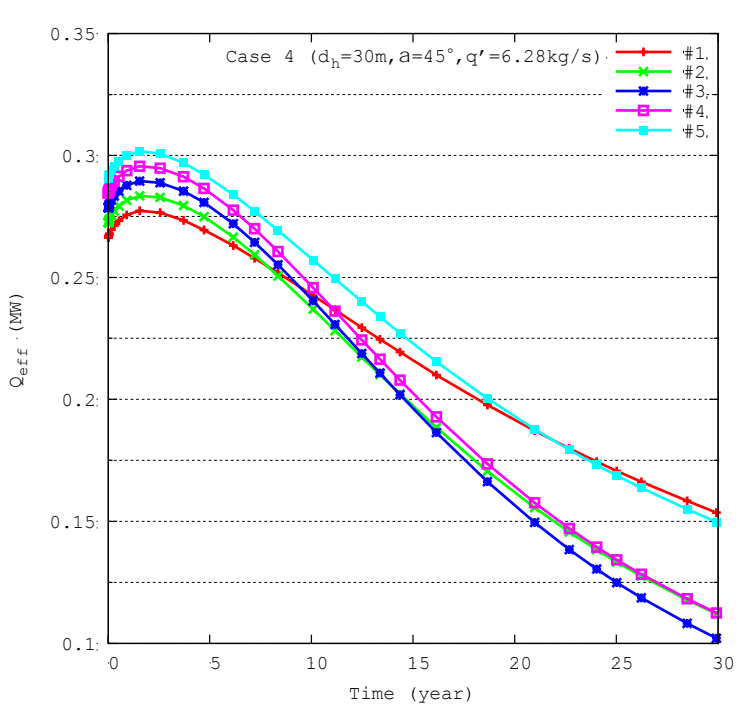

(b)

1 Figure 10 Time histories of (a) the produced fluid temperature from the five production boundaries

2 and (b) the corresponding effective electric power rates for Case $4\left(d_{\mathrm{h}}=30 \mathrm{~m}, \alpha=45^{\circ}, \dot{q}=6.28 \mathrm{~kg} / \mathrm{s}\right)$.

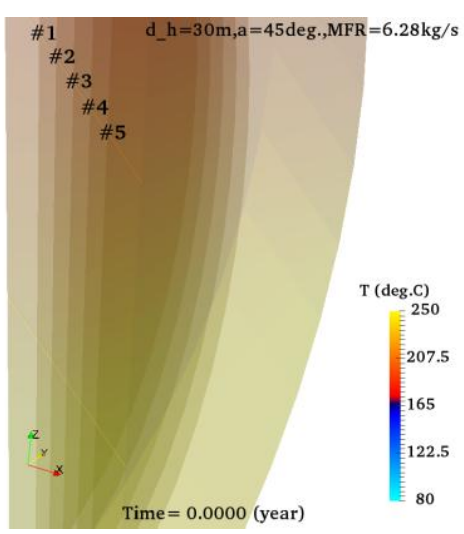

(a)

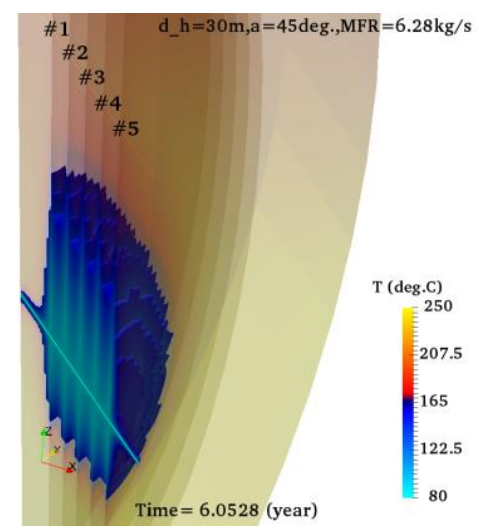

(d)

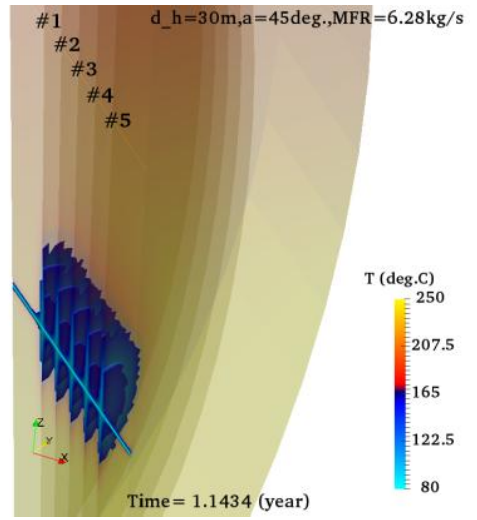

(b)

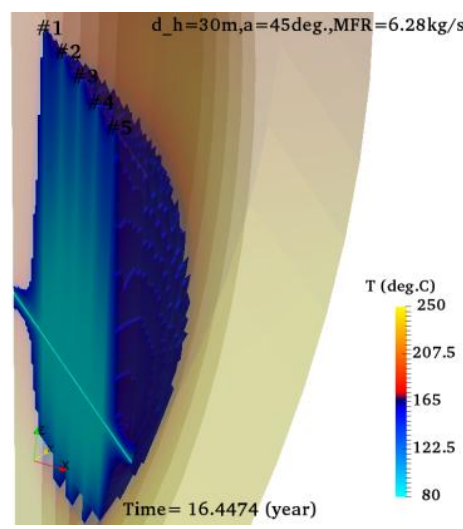

(e)

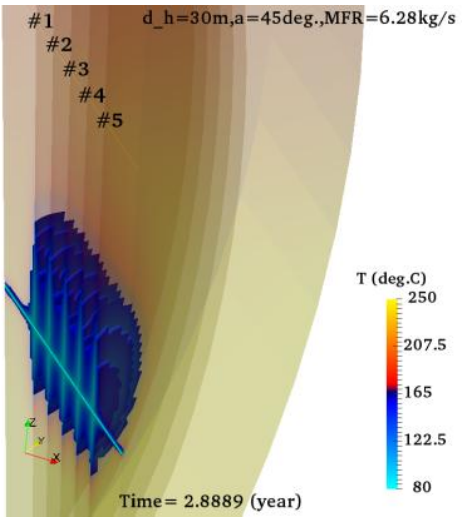

(c)

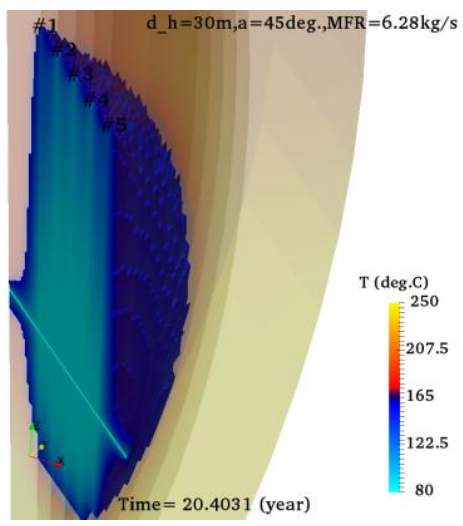

(f)

Figure 11 Evolution of the cooled regions in the reservoir for Case $4\left(d_{\mathrm{h}}=30 \mathrm{~m}, \alpha=45^{\circ}\right.$, $\dot{q}=6.28 \mathrm{~kg} / \mathrm{s})$. 


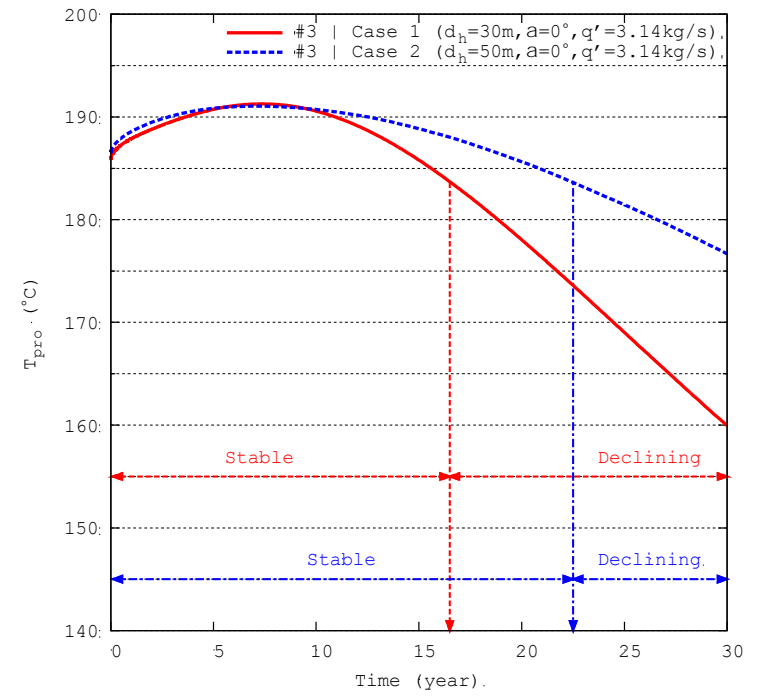

(a)

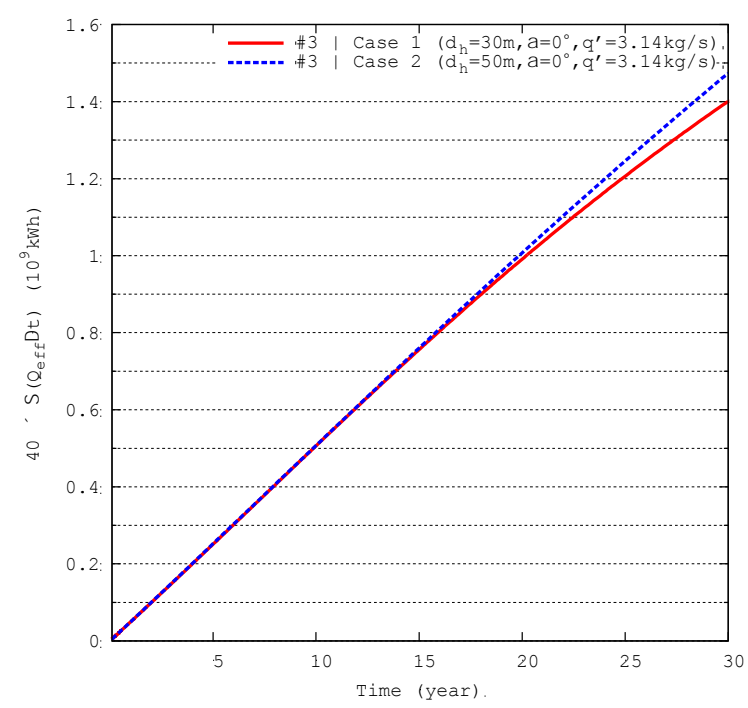

(c)

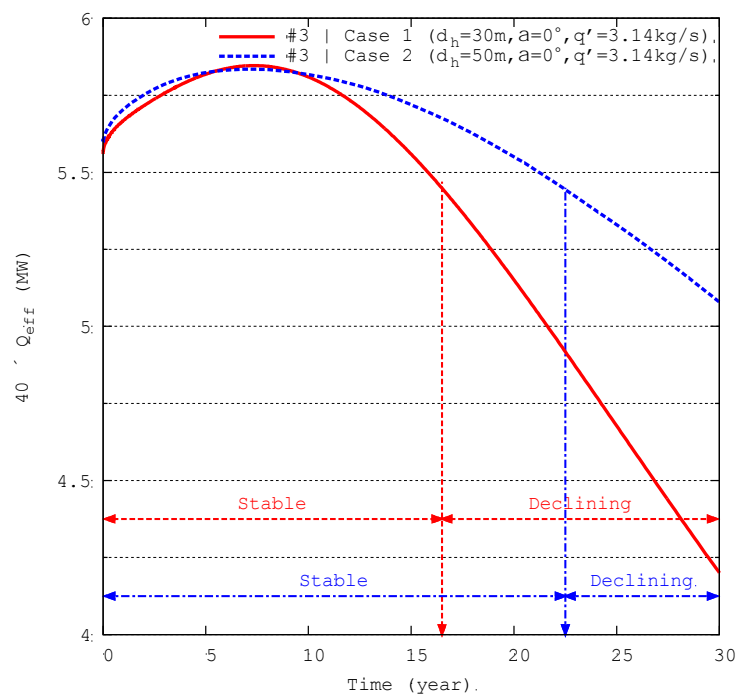

(b)

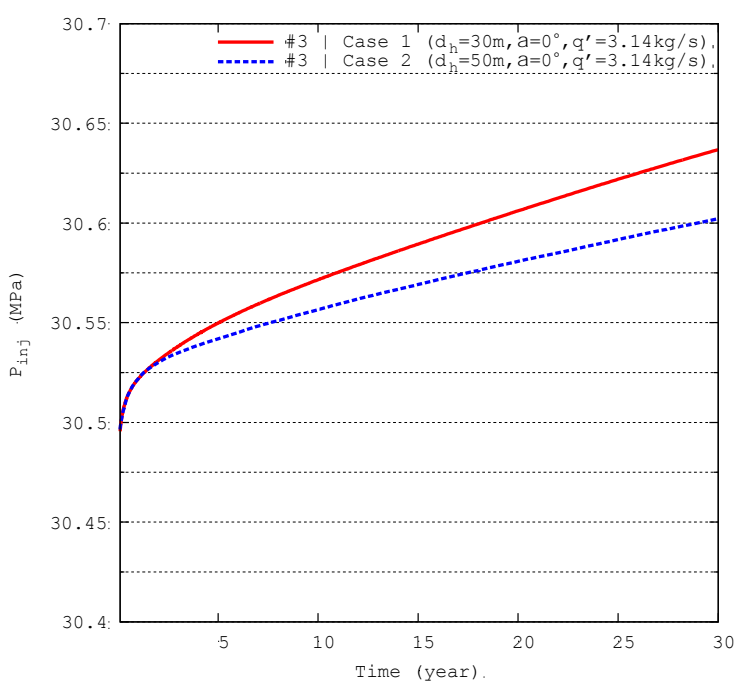

(d)

1 Figure 12. Comparison of the performance metrics of a 30-year EGS heat extraction process with re2 spect to $d_{h}$, with $\alpha=0^{\circ}$ and $\dot{q}=3.14 \mathrm{~kg} / \mathrm{s}$ per fracture in both Test Case 1 and 2. 


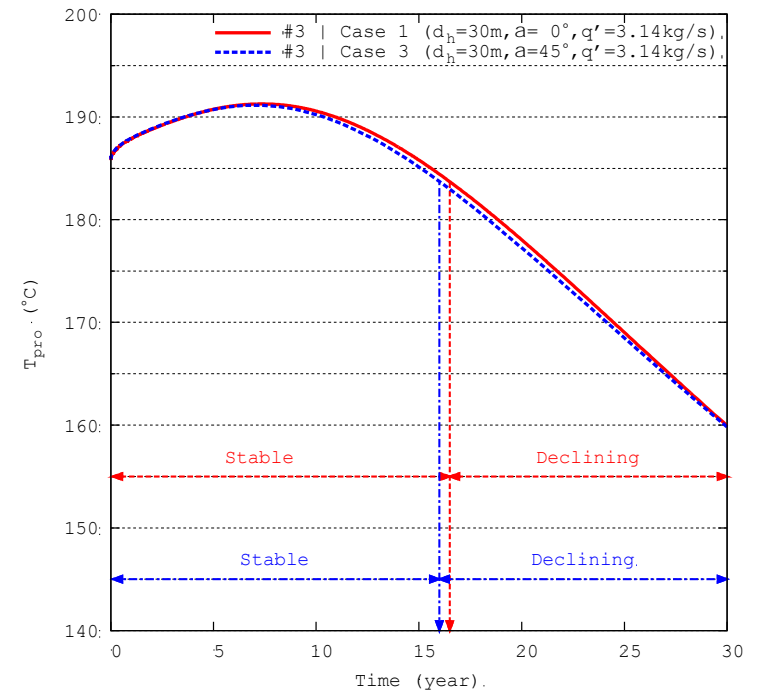

(a)

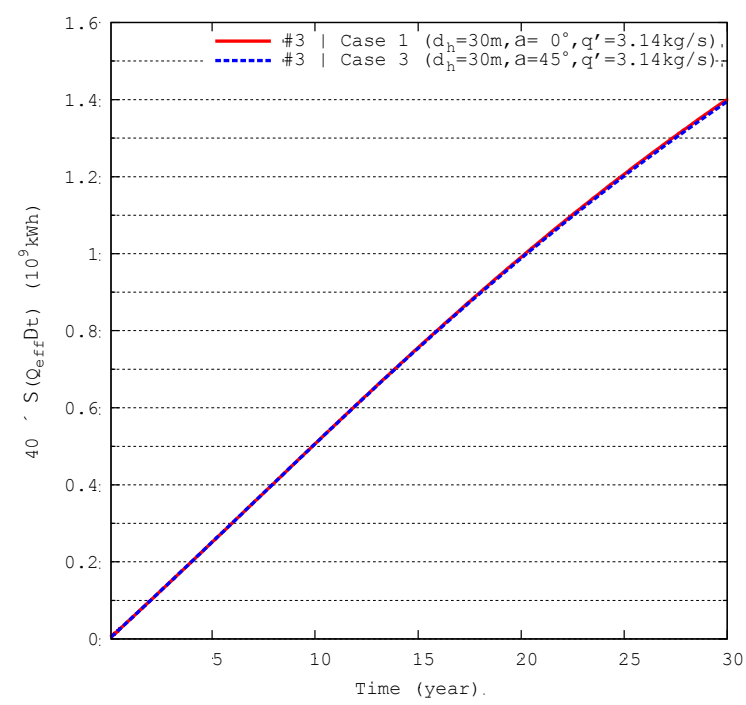

(c)

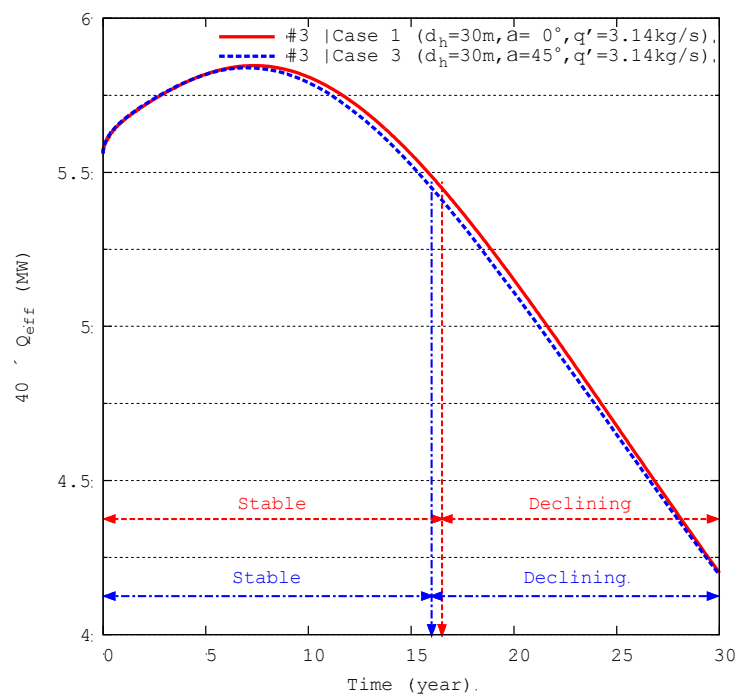

(b)

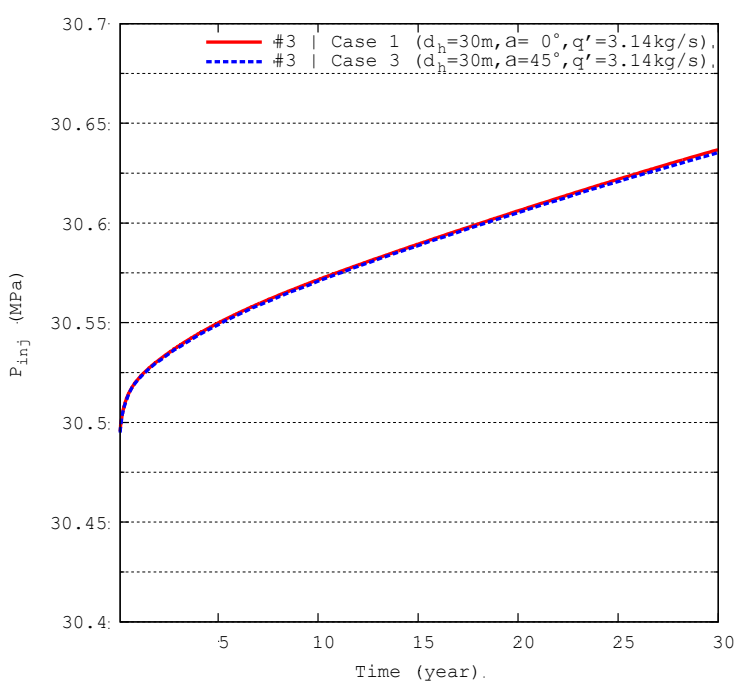

(d)

1 Figure 13. Comparison of the performance metrics of a 30-year EGS heat extraction process with re2 spect to $\alpha$, with $d_{h}=30 \mathrm{~m}$ and $q=3.14 \mathrm{~kg} / \mathrm{s}$ per fracture in both Test Case 1 and 3 . 


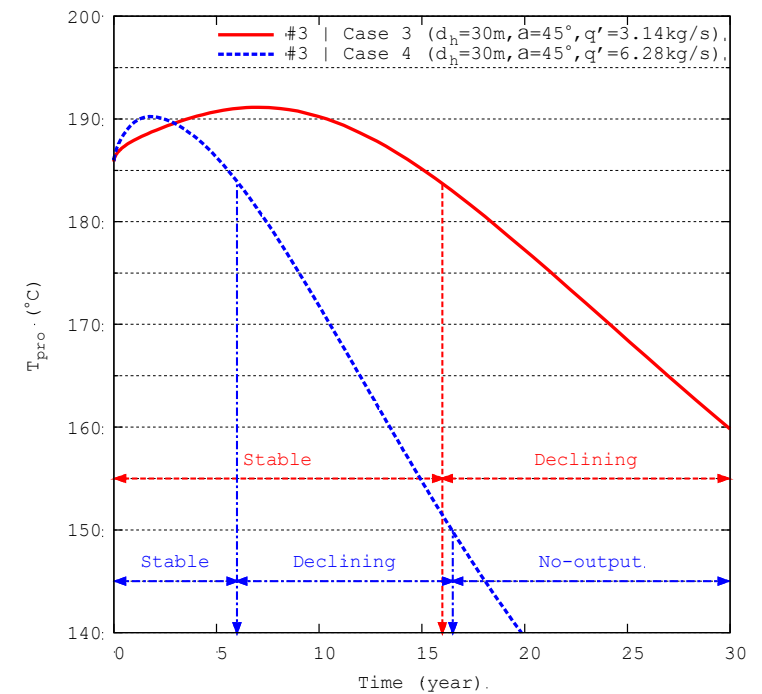

(a)

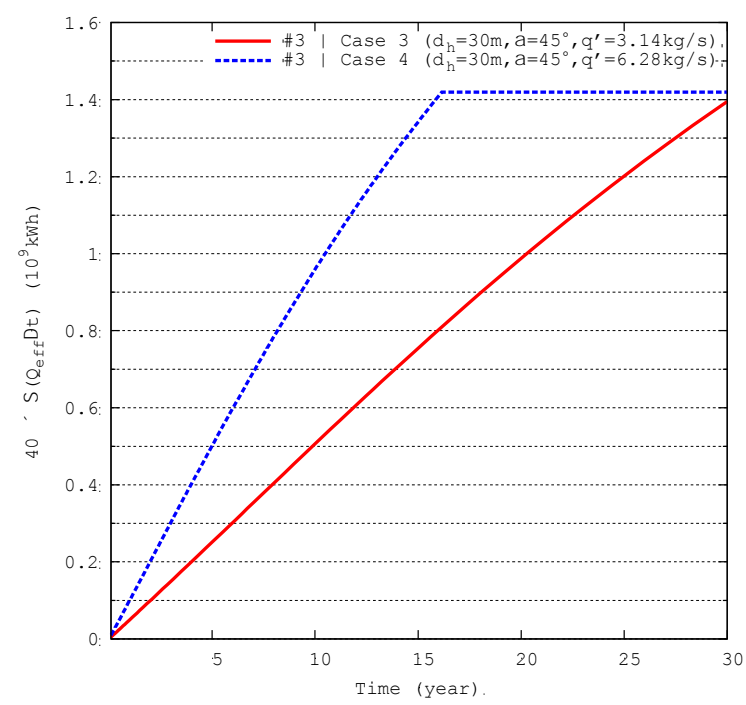

(c)

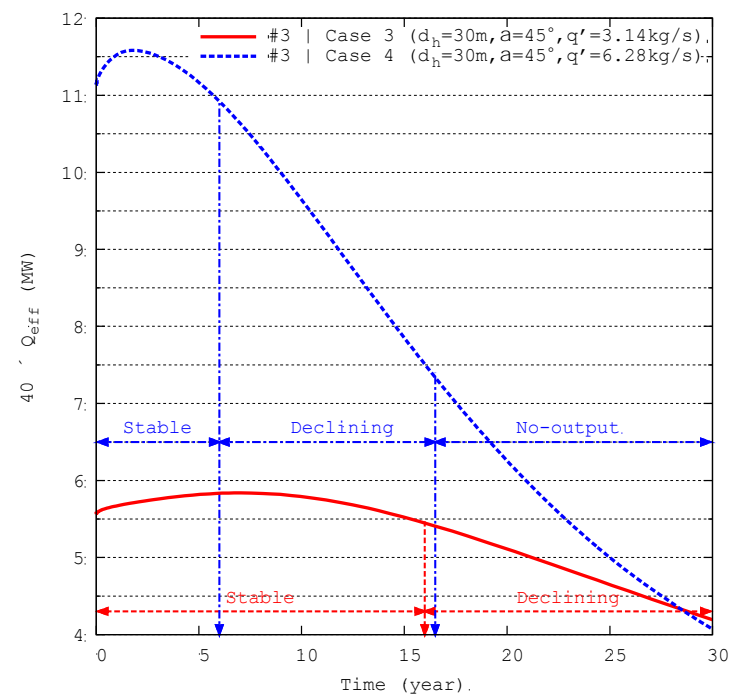

(b)

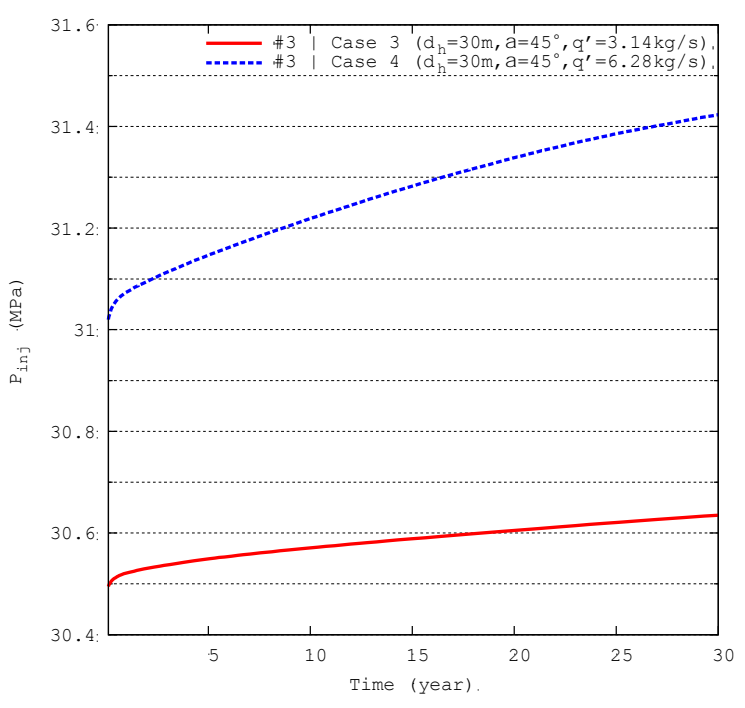

(d)

1 Figure 14. Comparison of the performance metrics of a 30-year EGS heat extraction process with re2 spect to q́ (per fracture), with $d_{h}=30 \mathrm{~m}$ and $\alpha=45^{\circ}$ in both Test Case 3 and 4. 


\section{CONCLUSIONS}

2 This work has presented the design, modeling, and evaluation of heat extraction based on a set of dou-

3 blet well layout schemes in a conceptual enhanced geothermal system. A hydrothermal model that fully

4 couples the fluid flow and heat transport has been used to model the water circulation and heat extrac-

5 tion process in fractured reservoirs. Apart from the horizontal and parallel well layout often seen in lit-

6 erature, an alternative layout with a downward deviating angle has been considered in this work. These

7 conceptual models were simulated using a newly developed, open-source, finite-element based geo-

8 thermal reservoir simulation code, FALCON. Simulation results of a 30 -year operation at a depth of $3 \mathrm{~km}$

9 and geothermal gradient of $65^{\circ} \mathrm{C}$ per $\mathrm{km}$ of depth have been presented. The main contribution of the

10 work is that the developed well layout schemes as well as the EGS heat extraction models have been

11 quantitatively verified and validated for a potential objective of industrial production-level heat produc-

12 tion, though further revision and calibration of the models will always be required upon more field data

13 being collected. In particular, the preferable well layout design parameters as well as the material prop-

14 erties suggested in this work match well with those suggested by others (i.e., Jung 2013), indicating the

15 general applicability of our conceptual models.

16 In addition, from the sensitivity study of the heat production to the equidistant horizontal spacing

17 between the large single wing fractures, $d_{h}$, the downward deviating angle for parallel doublet wells, $\alpha$, 18 and the injection mass flow rate per fracture, $q$, we have found that:

19 1) The inter-fracture interference is sensitive to the choice of $d_{h}$, and the long-term performance of

20 heat production may be significantly undermined if $d_{h}$ is too small. Though the inter-fracture in-

21 terference could be minimized conceptually by setting $d_{\mathrm{h}}$ large enough, yet it may usually cost

22 substantially more for horizontal well drilling than it could probably pay back by eliminating such

23 the inter-fracture interference (e.g., when $d_{h}$ has to be at least about $120 \mathrm{~m}$ as found in Li \& Lior 
2015). Thus regarding the capital investment, the inter-fracture interference does not have to be necessarily avoided when designing the $d_{h}$ in practice.

2) Long-term EGS performance is practically insensitive to choice of $\alpha$, if the initial average temperature of the fractured reservoir is the same. Nevertheless, a well layout with a downward deviating angle may be considered in practice, as it is not economical or possible for the initial vertical drilling to reach a desirable depth and production temperature directly, due to the uncertain in situ stress. Therefore upon the field data from preliminary drilling test, a deviating angle of the specific subsurface environment for simulation and evaluation.

3) All of the key EGS performance metrics are sensitive to q́. In practice, an optimal q́ for the best long-term EGS operation depends on many important reservoir conditions, such as the fracture permeability, and the spatial extend of fractures. A proper $q$ not only helps avoid early thermal drawdown, but also leads to an economically favorable average increment of $P_{\text {inj }}$ during the operation so as to reduce the electric power for water re-injection.

Finally, we would like to note that the study of EGS is yet at a young stage despite the R\&D efforts

17 over the past 30 years. As no EGS project has been economically successful at the industrial production

18 level, there is still a long way before EGS energy could be demonstrated as a stable source of renewable

19 energy. So far as the EGS conceptual design is concerned, we would caution that without considering

20 the plausible geo-techniques that may be employed to create the desirable fractures, it will still be very

21 difficult to prove the feasibility of even a numerically verified \& validated EGS heat production model.

22 Aiming to further enhance our understanding of the EGS systems, our future study will be focused on

23 the coupled thermo-hydro-mechanical processes that include the fracture creation and propagation. 


\section{ACKNOWLEDGEMENT}

2 The work described in this paper was supported by the U.S. Department of Energy, under DOE Idaho

3 Operations Office Contract. Accordingly, the U.S. Government retains a nonexclusive, royalty-free li-

4 cense to publish or reproduce the published form of this contribution, or allow others to do so, for U.S.

5 Government purposes. This information was prepared as an account of work associated by an agency of

6 the U.S. Government. Neither the U.S. Government nor any agency thereof, nor any of their employees,

7 makes any warranty, express or implied, or assumes any legal liability or responsibility for the accuracy,

8 completeness, or usefulness of any information, apparatus, product, or process disclosed, or represents

9 that its use would not infringe privately owned rights. References herein to any specific commercial

10 product, process, or service by trade name, trademark, manufacturer, or otherwise, does not necessarily

11 constitute or imply its endorsement, recommendation, or favoring by the U.S. Government or any agen-

12 cy thereof. The views and opinions of authors expressed herein do not necessarily state or reflect those

13 of the U.S. Government or any agency thereof.

\section{REFERENCE}

15 Avdonin, N. A. (1964): Some Formulas for Calculating the Temperature Field of a Stratum Subject to 16 Thermal Injection, Neft'i Gaz, 3, 37-41.

17 Barbier, E. (2002): Geothermal Energy Technology and Current Status: An Overview, Renewable and Sus18 tainable Energy Reviews, 6(1), 3-65.

Batchelor, A. S. (1981): The Creation of Hot Dry Rock Systems by Combined Explosive and Hydraulic Fracturing, In proceedings of the International Conference on Geothermal Energy, May 1982. Florence, Italy. BHRA Fluid Eng. Bedford (1982), pp. 321-342.

Blacker, T. D., Bohnhoff, W. J., \& Edwards, T. L. (1994): CUBIT Mesh Generation Environment. Volume 1: Users Manual (No. SAND--94-1100). Sandia National Labs., Albuquerque, NM (United States).

24 Blackwell, D. D., Kelley, S., \& Steele, J. L. (1992): Heat Flow Modeling of the Snake River Plain, Idaho. US Department of Energy Report for Contract DE-AC07-761DO1570, 109.

26 Brownell, D. H., Garg, S. K., \& Pritchett, J. W. (1977): Governing Equations for Geothermal Reservoirs. 
Bujakowski, W., Barbacki, A., Miecznik, M., Pająk, L., Skrzypczak, R., \& Sowiżdżał, A. (2015): Modeling Geothermal and Operating Parameters of EGS Installations in the Lower Triassic Sedimentary Formations of the Central Poland Area, Renewable Energy, 80, 441-453.

Chen, J., \& Jiang, F. (2015): Designing Multi-Well Layout for Enhanced Geothermal System to Better Exploit Hot Dry Rock Geothermal Energy, Renewable Energy, 74, 37-48.

Chen, J., \& Jiang, F. (2016): A Numerical Study of EGS Heat Extraction Process Based on a Thermal NonEquilibrium Model for Heat Transfer in Subsurface Porous Heat Reservoir, Heat and Mass Transfer, 52(2), 255-267.

Cooper, J. R., \& Dooley, R. B. (2008): Release of the IAPWS Formulation 2008 for the Viscosity of Ordinary Water Substance.

Cornet, F. H. (1989): Experimental Investigations of Forced Fluid Flow through a Granite Rock Mass. In proceedings of 4th International Seminar on the Results of EC Geothermal Energy Demonstration, Florence, Italy, April 27-30, 1989, pp. 189-204.

Duchane, D. (1990): Hot Dry Rock: A Realistic Energy Option, Bulletin of the Geothermal Resources Council, 19(3), 83-88.

Duchane, D., \& Brown, D. (2002): Hot Dry Rock (HDR) Geothermal Energy Research and Development at Fenton Hill, New Mexico, Geothermal Heat Center Bulletin.

Faust, C. R., \& Mercer, J. W. (1979a): Geothermal Reservoir Simulation: 1. Mathematical Models for Liquid- and Vapor-Dominated Hydrothermal Systems, Water Resources Research, 15(1), 23-30.

Faust, C. R., \& Mercer, J. W. (1979b): Geothermal reservoir simulation: 2. Numerical Solution Techniques for Liquid- and Vapor-Dominated Hydrothermal Systems, Water Resources Research, 15(1), 31-46.

Held, S., Genter, A., Kohl, T., Kölbel, T., Sausse, J., \& Schoenball, M. (2014): Economic Evaluation of Geothermal Reservoir Performance through Modeling the Complexity of the Operating EGS in Soultzsous-Forêts, Geothermics, 51, 270-280.

Jiang, F., Chen, J., Huang, W., \& Luo, L. (2014): A Three-Dimensional Transient Model for EGS Subsurface Thermo-Hydraulic Process, Energy, 72, 300-310.

Jiang, F., Luo, L., \& Chen, J. (2013): A Novel Three-Dimensional Transient Model for Subsurface Heat Exchange in Enhanced Geothermal Systems, International Communications in Heat and Mass Transfer, $41,57-62$.

Jung, R. (2013): EGS - Goodbye or Back to the Future, in proceedings of International Society for Rock Mechanics (ISRM) International Conference for Effective and Sustainable Hydraulic Fracturing, Brisbane, Australia.

Kohl, T., \& Hopkirk, R. J. (1995): "FRACure" - A Simulation Code for Forced Fluid Flow and Transport in Fractured, Porous Rock, Geothermics, 24(3), 333-343.

McDermott, C. I., Randriamanjatosoa, A. R., Tenzer, H., \& Kolditz, O. (2006): Simulation of Heat Extraction from Crystalline Rocks: The Influence of Coupled Processes on Differential Reservoir Cooling, Geothermics, 35(3), 321-344.

Murphy, H. D. (1985): Hot Dry Rock Phase II Reservoir Engineering, Tech. Repo. (No. LA-UR-85-3334). Los Alamos National Laboratory, New Mexico, USA.

Li, M., \& Lior, N. (2015): Analysis of Hydraulic Fracturing and Reservoir Performance in Enhanced Geothermal Systems, Journal of Energy Resources Technology, 137(4), 041203. 
Plummer, M., Xia, Y., Podgorney, R., Mattson, E., Huang, H. \& Ghassemi, A. (2016): Primary Constraints on the Design of an Enhanced Geothermal System Reservoir. In 50th US Rock Mechanics / Geomechanics Symposium, Houston, Texas, USA.

Podgorney, R., Huang, H., \& Gaston, D. (2010): A Fully Coupled, Implicit, Finite Element Model for Simultaneously Solving Multiphase Fluid Flow, Heat Transport, and Rock Deformation. Geothermal Resources Council Transactions, 34: 427-432.

Podgorney, R. K., Huang, H., Lu, C., Gaston, D., Permann, C., Guo, L., \& Andrs, D. (2011). FALCON: A Physics-Based, Massively Parallel, Fully-Coupled, Finite Element Model for Simultaneously Solving Multiphase Fluid Flow, Heat Transport, and Rock Deformation for Geothermal Reservoir Simulation, Idaho National Laboratory Report. Idaho National Laboratory Report INL/EXT-11-23351.

Polsky, Y., Capuano, L., Finger, J., Huh, M., Knudsen, S., Mansure, A. J., ... \& Swanson, R. (2008): Enhanced Geothermal Systems (EGS) Well Construction Technology Evaluation Report. Sandia National Laboratories, Sandia Report, SAND2008-7866, 1-108.

Pruess, K., Oldenburg, C. M., \& Moridis, G. J. (1999): TOUGH2 User's Guide Version 2, Lawrence Berkeley National Laboratory.

Rutqvist, J., Wu, Y. S., Tsang, C. F., \& Bodvarsson, G. (2002): A Modeling Approach for Analysis of Coupled Multiphase Fluid Flow, Heat Transfer, and Deformation in Fractured Porous Rock, International Journal of Rock Mechanics and Mining Sciences, 39(4), 429-442.

Smith, M. C., Aamodt, R. L., Potter, R. M., \& Brown, D. W. (1975): Manmade Geothermal Reservoirs, Tech. Repo. No. LA-UR-75-953. CONF-750525-6. Los Alamos Scientific Laboratory, New Mexico, USA.

Tester, J. W., Brown, D. W., \& Potter, R. M. (1989): Hot Dry Rock Geothermal Energy - A New Energy Agenda for the 21st Century, Tech. Repo. No. LA-11514-MS. Los Alamos National Laboratory, New Mexico, USA.

Wagner, W., Cooper, J. R., Dittmann, A., Kijima, J., Kretzschmar, H. J., Kruse, A., \& Willkommen, T. (2000): The IAPWS industrial formulation 1997 for the thermodynamic properties of water and steam, Journal of Engineering for Gas Turbines and Power, 122(1), 150-184.

Reichenberger, V., Jakobs, H., Bastian, P., \& Helmig, R. (2006): A Mixed-Dimensional Finite Volume Method for Two-Phase Flow in Fractured Porous Media, Advances in Water Resources, 29(7), 10201036.

Sanyal, S. K., \& Butler, S. J. (2005): An Analysis of Power Generation Prospects from Enhanced Geothermal Systems, Geothermal Resources Council Transactions, 29, 131-8.

U.S. Department of Energy Office of Energy Efficiency \& Renewable Energy (2008): An Evaluation of Enhanced Geothermal Systems Technology, <https://www1.eere.energy.gov/geothermal/pdfs/evaluation_egs_tech_2008.pdf> [Accessed February 2016].

Xia, Y., \& Podgorney, R. (2015): FALCON - a Finite Element Geothermal Reservoir Simulation Code, source code available at < https://github.com/idaholab/falcon > [Accessed February 2016].

Xia, Y., Plummer, M., Podgorney, R., \& Ghassemi, A. (2016a): An Assessment of Some Design Constraints on Heat Production of a 3D Conceptual EGS Model Using an Open-Source Geothermal Reservoir Simulation Code. In 41st Stanford Geothermal Workshop, Stanford, California, USA, February 2016. 
Xia, Y., Podgorney, R., \& Huang, H. (2016b): Assessment of a Hybrid Continuous / Discontinuous Galerkin Finite Element Code for Geothermal Reservoir Simulations, Rock Mechanics and Rock Engineering, published (online), March 2016, DOI: 10.1007/s00603-016-0951-y

Xing, H., Liu, Y., Gao, J., \& Chen, S. (2015): Recent Development in Numerical Simulation of Enhanced Geothermal Reservoirs, Journal of Earth Science, 26(1), 28-36.

Zeng, Y. C., Su, Z., \& Wu, N. Y. (2013a): Numerical Simulation of Heat Production Potential from Hot Dry Rock by Water Circulating through Two Horizontal Wells at Desert Peak Geothermal Field, Energy, 56, 92-107.

Zeng, Y. C., Wu, N. Y., Su, Z., Wang, X. X., \& Hu, J. (2013b): Numerical Simulation of Heat Production Potential from Hot Dry Rock by Water Circulating through a Novel Single Vertical Fracture at Desert Peak Geothermal Field, Energy, 63, 268-282.

Zyvoloski, G. (2007): FEHM: A Control Volume Finite Element Code for Simulating Subsurface MultiPhase Multi-Fluid Heat and Mass Transfer, Los Alamos Unclassified Report LA-UR-07-3359. 